\title{
La cerámica medieval y moderna de la alquería de la Villeta (Monda, Málaga)
}

\author{
Medieval and early modern pottery from "Alqueria de la Villeta", Monda \\ (Málaga)
}

Antonio Ordóñez frías *

\begin{abstract}
RESUMEN
En este trabajo exponemos las conclusiones derivadas del estudio cerámico realizado en la alquería de la Villeta, Monda-Málaga-. La peculiaridad de este enclave estriba en que se trata de un espacio de hábitat con un origen nazarí, y que tuvo una continuidad poblacional en los períodos mudéjar y morisco, siendo abandonada en el 1572 y no volviéndose a reutilizar como lugar de poblamiento. De ahí la importancia del registro cerámico que nos muestra el tránsito de tipologías y decoraciones de origen almohade-nazarí, a otras en que la influencia castellana, y especialmente, las peculiaridades de la cultura moriscas, van a ir caracterizando a dichos conjuntos cerámicos.
\end{abstract}

Palabras clave: Alquería, nazarí, morisco, registro cerámico

\begin{abstract}
In this paper we show the results of a study on the pottery found at the "Alqueria de la Villeta", in Monda (Málaga). A village originated during the nasri period, it was inhabitated along the sixteenth century by the mudejar and morisco population, being abandoned definitively in 1572. The importance of this pottery deposit is that displays the transition from the almohad-nasri typologies to castilian influenced ones, including those associated to the morisco culture, changing the ceramic yield.
\end{abstract}

Key words: Village, nasri, morisco, pottery evidence

\section{INTRODUCCIÓN}

La alquería de la Villeta estaba situada en el término municipal de Monda (Málaga) (Fig. 1) muy cerca de su actual centro urbano y entre los municipios de Coín y Marbella, sirviendo como paso natural que unía la subcuenca de río Grande con la costa marbellí. Su situación estratégica hace que desde, al menos, el período almohade, existiera en la villa un importante hisn.

La toma de Teba por los castellanos en 1330 repercutió en el aumento

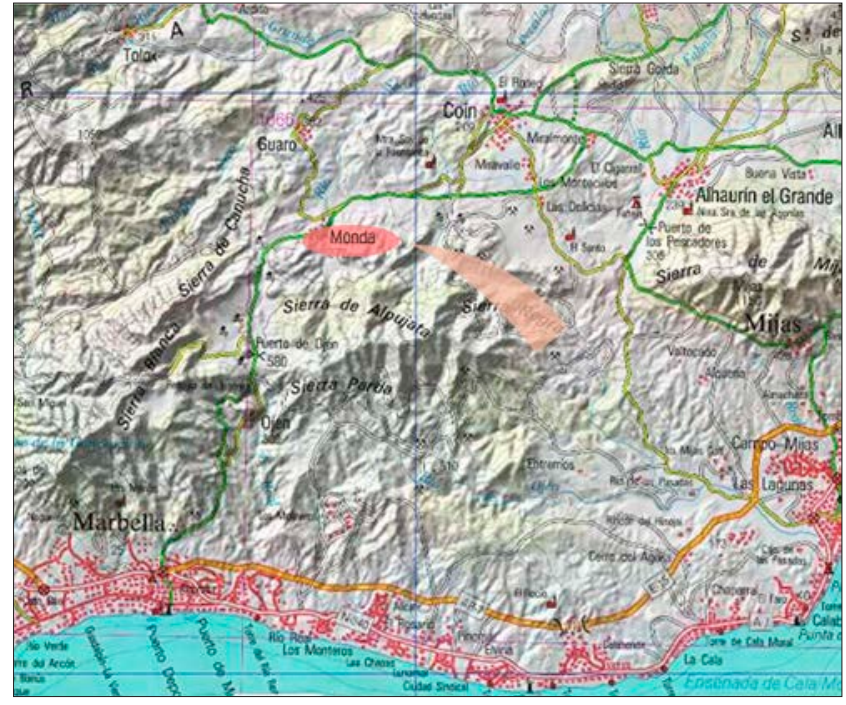

Fig. 1. Situación de Monda dentro de la provincia de Málaga.

* Universidad de Cádiz-Instituto de Estudios de Ronda y la Serranía. 
de las incursiones sobre la parte occidental de la actual provincia de Málaga. Pensamos que ya en la segunda mitad del siglo XIV, y especialmente en el primer cuarto del siglo XV tras la caída de Antequera en 1409, se produjo el abandono de muchas de estas pequeñas alquerías (cuando no su destrucción por las algaradas). Su población emigró hacia lugares más seguros, como serían los casos de Dakwan (actual Coín), Monda, Tolóx - Casarabonela, que poseían estructuras defensivas sólidas y un número de población suficiente para plantear una defensa eficaz. En este contexto fue donde se creó la alquería de la Villeta como consecuencia del abandono de una serie de pequeños núcleos rurales circundante al hisn de la Villeta, como la Moheda, Alpuxata, el Moxnar o Guajar, ante la protección que ofrecía dicha estructura defensiva (Fig. 2).

Las noticias que tenemos sobre la Monda medieval son muy tardías y proceden de fuentes castellanas. Ya se hace referencia a la villa en algunas de las frecuentes cabalgadas que los cristianos realizaron en la comarca. Digna de destacar es la incursión que se produjo en el año 1483 comandadas por el marqués de Cádiz y por el maestre de Santiago:
"E talaron la çibdad así de panes como de huertas e oliuares e vinnas e todo cuanto pudieron alcançar, allende de ella, e a Cártama e a Campanillas e a Churriana e a Pupiana e a Laulyn e a Coym e a Fadala e Benamaquís e a Monda e Tolox, e todo el valle de Santa María, e a Guaro e Caçarabonela e Álora donde los moros reçibieron gran danno. E de ally salieron a los prados de Antequera..." (CARRIAZO RUBIO, 2003: 233).

En 1485, con el cerco por las tropas castellanas de Coín, también se realiza una breve mención del lugar: "...el Rey mando poner cerco sobre la villa de Cartama é Coin, vinieron gran multitud de dellos (moros) a la villa de Monda..." (HERNANDO DE PULGAR, 1780: 245), aunque siguió en manos musulmanas. Pero el hito fundamental que precipitó la sumisión de toda la comarca serrana fue la rendición de Ronda en 1485. Una serie de villas enviaron mensajeros a los Reyes Católicos para pactar su rendición. Así ocurre con Monda:

"El rey dio seguro que las villas aquí nombradas embiaran a pedir, con condición que luego entregasen las fortalezas de cada una de ellas [...] E la villa de Monda hé su fotaleza a Hurtado de Luna" (HERNANDO DE PULGAR, 1780: 254).

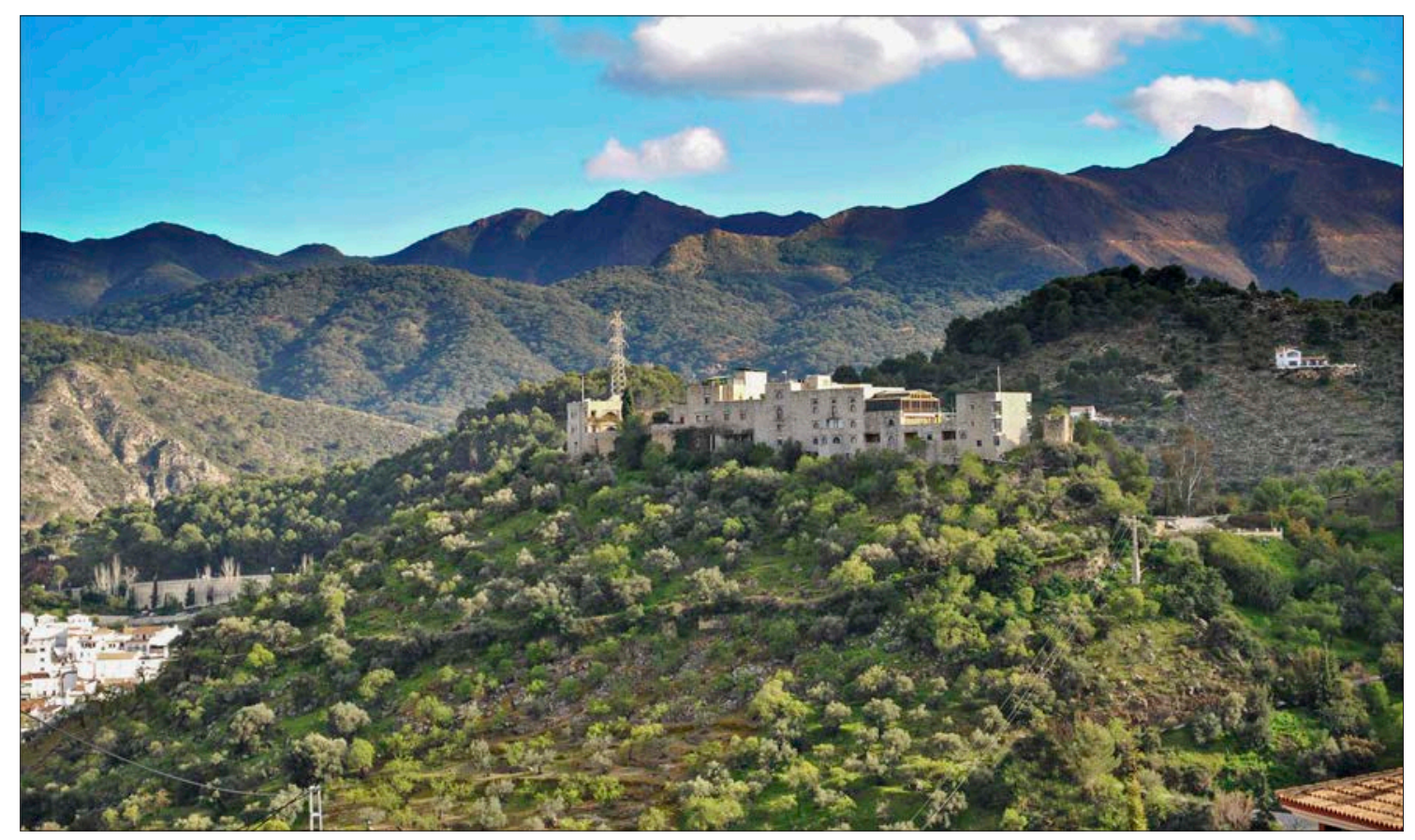

Fig. 2. Hisn de la Villeta y cerca defensiva en su parte inferior. Entre ambos estaba ubicada la alquería. 
Esta sumisión, sin resistencia armada, hace que su población islámica adquiriera el estatuto de mudéjares, conservando en buena medida sus propiedades, además de su religión y costumbres. Así queda reflejado en el Repartimiento de 1487 (BENJARANO ROBLES, 2000: 209-219), en que se otorgan a cristianos viejos la totalidad de las tierras procedentes de bona vacantia, además de las mercedes reales y las propiedades con las que se dota a la iglesia para su fábrica y mantenimiento. Parece que estas donaciones supusieron un porcentaje reducido sobre el total de las tierras cultivadas de Monda, como queda reflejado en el Apeo de 1572: "Pareze que todas las tierras de secano que son en el dicho thérmino de Monda es dozientas y setenta fanegadas todas de moriscos. "(URBANO, 1998: 263). Algo similar ocurre con la superficie irrigada, también mayoritariamente en manos moriscas.

Es importante recalcar que este espacio de hábitat no tuvo, durante todo el siglo XVI, ninguna familia de cristianos viejos habitando en su solar, a diferencia del arrabal, donde eran frecuentes las vecindades entre ambos colectivos. Por lo tanto, no hubo "contaminación material" directa de la cultura dominante sobre la morisca dentro de la alquería de la villeta.

Con este trabajo pretendemos detectar los posibles cambios que se produjeron en las tipologías, decoraciones y usos de los artefactos cerámicos durante los períodos tardonazarí y morisco en la comarca objeto de nuestro estudio, relacionándolos con la tradición cultural andalusí y teniendo en cuenta la creciente influencia aculturadora castellana, aunque sin desdeñar la propia evolución interna del último reino musulmán de la Península y de sus herederos, los moriscos. Estas profundas transformaciones socio-económicas y políticas también contribuyeron a la desarticulación espacial como consecuencia de la conquista castellana del territorio y de la expulsión de la población islámica de buena parte de este, lo que alteró significativamente el mapa de los antiguos centros alfareros nazaríes y de las redes de distribución relacionados con estos. Por tanto también pretendemos averiguar cómo se reorganizó la producción cerámica y cuáles fueron sus principales focos productivos.

\section{LA ACTIVIDAD ARQUEOLÓGICA DE 1990}

La excavación parcial de este espacio residencial fue efectuada en 1990 , en una actuación arqueológica de urgencia ejecutada por los arqueólogos Acién Almansa y Rambla Torralbo y requerida por la entonces Dirección General de Bienes Culturales de la Junta de Andalucía ante un proyecto de edificación sobre la estructura del hisn de la Villeta, dentro de cuyo albacar se encontraba la alquería del mismo nombre. Por lo tanto el complejo defensivo se componía de dos elementos bien diferenciados. El hisn era el recinto más elevado, coronando la explanada superior del cerro y con una extensión aproximada de 130 X 13 metros (Fig. 3). El segundo elemento, o

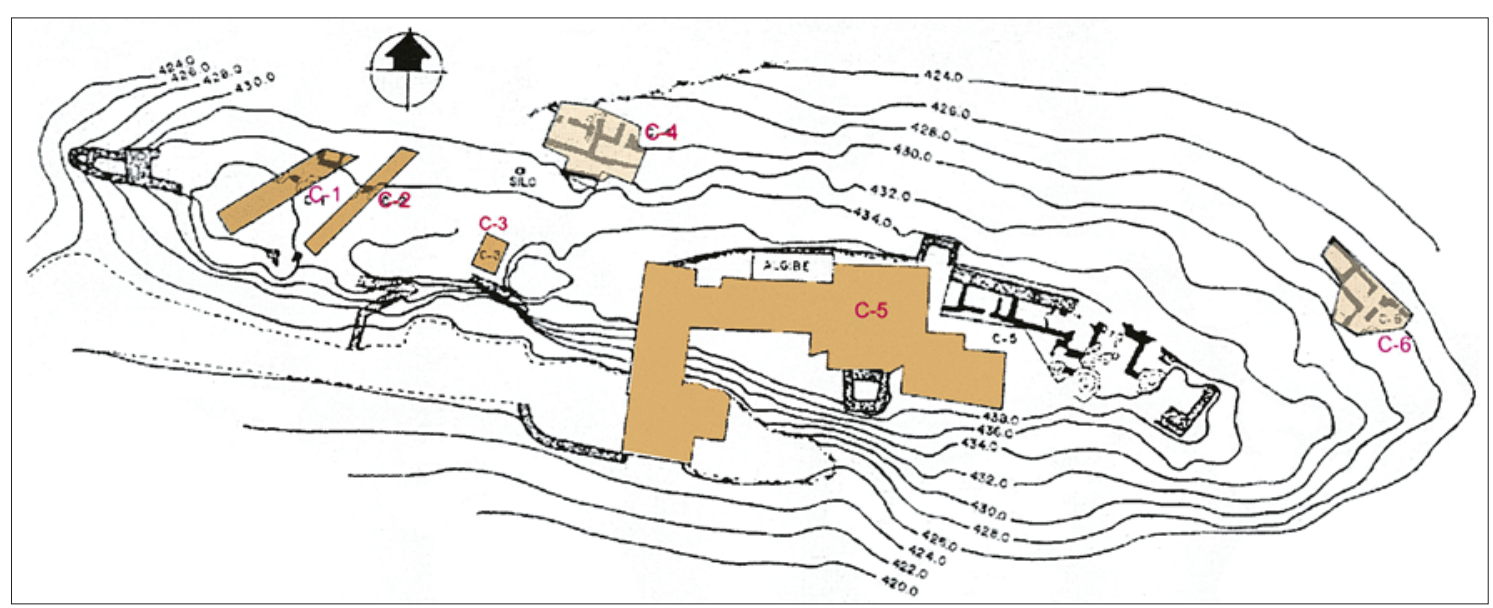

Fig. 3. Planta de la excavación. Los cortes 4 y 6 pertenecen a la alquería (ACIÉN Y RAMBLA, 1990-91: 283). 
albacar, arranca de sus extremos, protegiendo parte de la ladera norte y con un perímetro de alrededor de 300 metros.

El yacimiento se enmarca en un polígono delimitado por las siguientes coordenadas:

Vamos a proceder a la descripción de los diversos cortes reincidiendo especialmente en los que se generaron en la alquería, zona objeto de nuestro estudio:

Corte 1. Está constituido por una zanja de 15 X 3 metros, orientada de SW a NE. Se distingue dos niveles, ambos con poca potencia estratigráfica. No se crearon divisiones en

La unidad básica utilizada en la excavación de 1990 fue el Corte (C) y este, a su vez, se divide en Unidades Espaciales (UE). Por último dentro de cada una de ellas existe otra subdivisión que se le denominó Nivel (N). Los cortes 1, 2, 3 y 5 pertenecen al hisn, mientras que el 4 y 6 corresponden con la alquería. En esta última los cortes se plantearon a modo de cuadrículas con unas dimensiones impuestas por la propia configuración abancalada del terreno ${ }^{1}$.

Es necesario tener en cuenta que la información que nos proporciona la estratigrafía, especialmente la relacionada con la alquería, es escasa y poco esclarecedora. Varios factores han contribuido a ello. El más importante es el elevado grado de pendiente en que se ubicó este espacio residencial, lo que provocó, tras su destrucción y abandono, una intensa erosión que incluso produjo, en algunos sectores, la desaparición total de la cubierta y el afloramiento de los niveles geológicos. Tal es el caso del C-4 en su extremo norte. También observamos como en el Corte 6 , de las cinco UE registradas, sólo se conserva material cerámico de la UE-2. Probablemente se trate de un extravío en el almacenamiento del material o de una perdida ${ }^{2}$. Otro factor que resta información es la ausencia de perfiles arqueológicos en los C-4 y C-6. Acién y Rambla sólo los realizan en el C-5, dado que este corte era el objeto fundamental de la investigación, en la que se partía de la hipótesis del probable origen califal del hisn. unidades espaciales debido a su escasa superficie con valor arqueológico, como ocurrirá también en los cortes 2 y 3.

Corte 2. Con un trazado casi paralelo al anterior y una extensión de 16,5 X 2 metros. Se recoge un solo estrato que coincide con el superior del C-1.

Corte 3. Se emplaza en una pequeña plataforma próxima a la zona edificada, con una cota superior al resto del albacary con una potencia estratigráfica que no sobrepasa los 40 centímetros y, por lo tanto, con un escaso material cerámico.

Corte 5. Es el más amplio realizado en la zona superior del cerro. Su superficie presenta un claro desnivel con el sector occidental a mayor altura que el sector oriental. Se estructura en nueve unidades espaciales que resumimos en tres: área de habitación, espacios abiertos, y zonas de vertidos. La primera posee dos niveles, el primero con cerámica nazarí y cristiana, y el segundo con algunos lotes de cronología almohade. En el segundo se distingue un solo corte con una cronología muy amplia que va desde el siglo XII al XV. Por último en la zona de vertidos se observa tres niveles, los dos primeros semejantes a los hallados en el área de habitación y un tercero en que se ha encontrado material de probable procedencia califal, aunque en un contexto de cronología posterior. En este corte se ha

\footnotetext{
1 La información de este apartado ha sido tomada, prácticamente en su totalidad, de la publicación que se efectuó de la excavación en la revista Mainake (ACIÉN y RAMBLA, 1990-1991: 273-276).

2 En marzo del 2013 se realizó una consulta telefónica con el arqueólogo M. Acién Almansa, confirmándonos que en todas las UE
} se había constatado la existencia de fragmentos cerámicos desconociendo el paradero de dicho material. 
recogido la mayoría del material cerámico estudiado en el hisn.

Corte 4 (Fig. 4). Se realizó en la parte de la alquería más próxima al albacar, con una pendiente notable, llegando a alcanzar los tres metros de desnivel en una longitud total de nueve metros, por lo que su potencia estratigráfica es escasa ya que ha sufrido un proceso erosivo intenso, muy acusado en su extremo norte donde ha desaparecido la totalidad de su nivel. En este sector aparecieron restos de dos viviendas separadas por una atarjea. Se dividen en seis unidades espaciales que coinciden con un habitáculo dentro de cada vivienda. Los trazados de estas son paralelos a las curvas de nivel, asentando ambas el muro sur sobre la roca la cual sirve de nivelación a modo de escalón formando parte de su alzado. Se reconoce un sólo nivel ${ }^{3}$ que tiene una gran similitud con el N-1 del C-5, el cual sería su equivalente aunque ambos se encuentran a diferentes cotas. Al igual que en el C-5, se han hallado cerámica de origen cristiano, así como de tradición andalusí. Dentro de dicho nivel se menciona un sustrato superficial formado por una cobertura de tierra obscura con escaso y variado material. Es un relleno típico de derrumbe que incluye materiales diversos y que parecen, mayoritariamente, vinculados con el siglo XVI. También se hace referencia a una "primera cava", con fragmentos cerámicos de cronología igualmente relacionada con los siglos XV y XVI. En la parte inferior de este nivel destaca la aparición in situ del zaguán de la casa situada al este de la atarjea, junto con una serie de tipologías vinculadas con artefactos cerámicos de exposición al fuego y de presentación de alimentos.

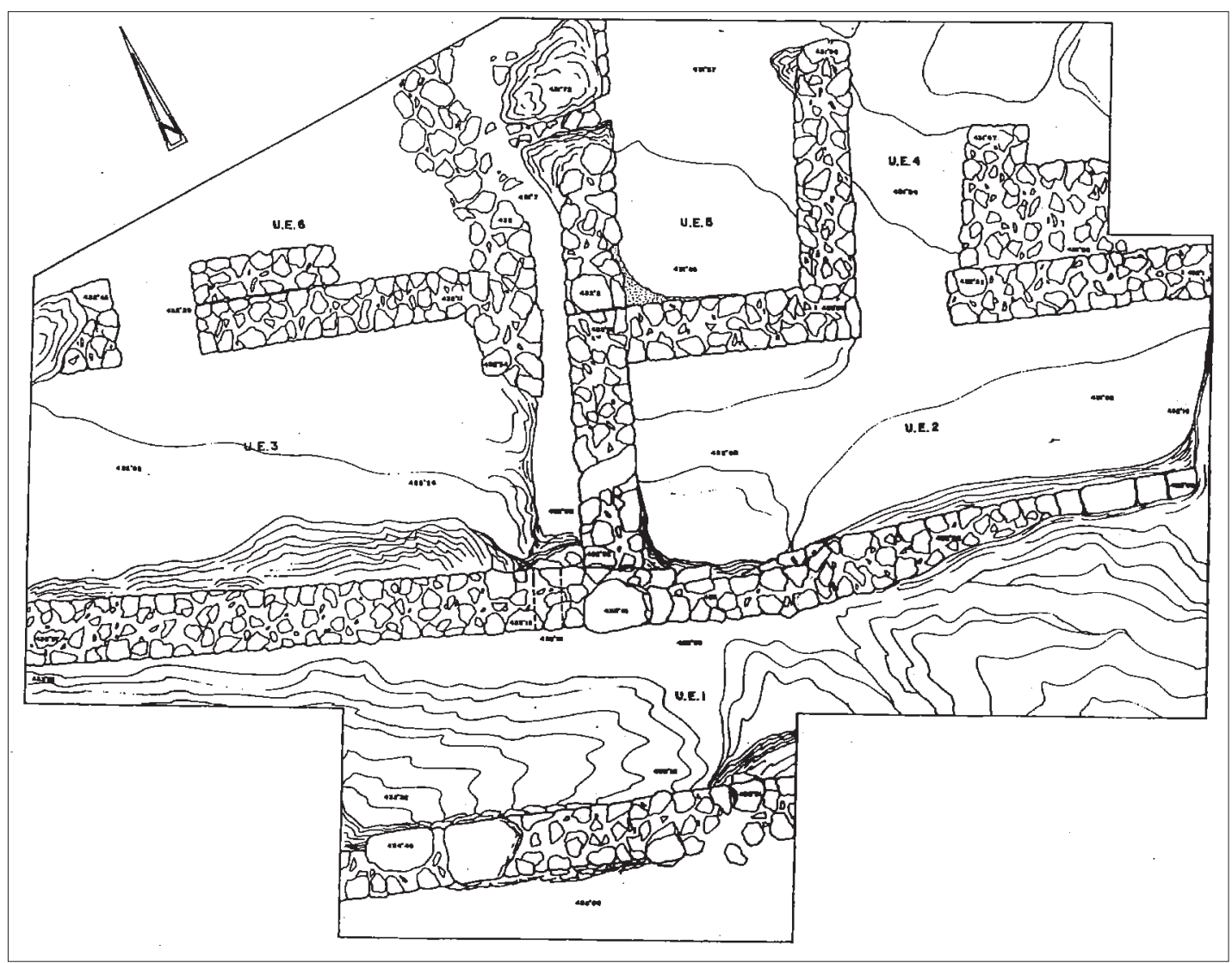

Fig. 4. Corte 4. Planta de parte de dos viviendas divididas por una atarjea (ACIÉN Y RAMBLA, 1990-91: 293).

3 Durante el trabajo de estudio cerámico realizado en Museo Arqueológico Provincial de Málaga se comprobó que todas las bolsas de materiales pertenecientes a los C-4 y C-6 están sigladas con el N-I. 
Corte 6 (Fig. 5). Es la parte de la alquería más próxima al hisn. En ella se encontró lo que quizás constituya una vivienda completa. Se aprecia la existencia de tres habitaciones contiguas en el sentido de las curvas de nivel y un probable patio, lo que podría corresponder con un espacio residencial de habitaciones en $L$ alrededor de un patio (GARCÍA PORRAS, 2001: 58). Su estratigrafía es similar a la del Corte-4, con un solo nivel dividiéndose en cinco unidades espaciales que también coinciden con las habitaciones de la vivienda. De interés es un lote recogido en una pequeña zanja conformada por el descenso brusco de la roca con tipologías nazaríes y también de origen almohade, como el hallazgo del único ejemplar de ataifor estampillado.

Con los resultados de dicha intervención arqueológica no se redactó ninguna tipo de memoria y sí un breve informe que se depositó en la Delegación de Cultura de Málaga. La normativa del momento no obligaba a este tipo de informes. Sin embargo Acién y Rambla realizaron un estudio sobre dicha excava- ción que fue publicado en la revista Mainake con el título: "La evolución de un hisn musulmán. Actuación arqueológica en el castillo de Monda" (ACIÉN Y RAMBLA, 1990-1991: 273-294) en el que nos hemos basado, parcialmente, para la realización de este trabajo de investigación.

\section{DESARROLLO METODOLÓGICO DE LA ACTIVIDAD}

Este estudio cerámico ha sido fruto de una actividad arqueológica puntual solicitada por este investigador y autorizado por la Delegación de Cultura de Málaga en el $2012^{4}$. Se efectuó sobre la totalidad del material cerámico que Acién y Rambla extrajeron de la excavación de 1990, es decir tanto de los cortes relacionados con el hisn, como de aquellas catas que se efectuaron en la alquería aunque, en este trabajo, sólo vamos a realizar el estudio del material cerámico procedente de dicho espacio residencial.

En primer lugar se analizaron los diversos fragmentos en su contexto estratigráfico

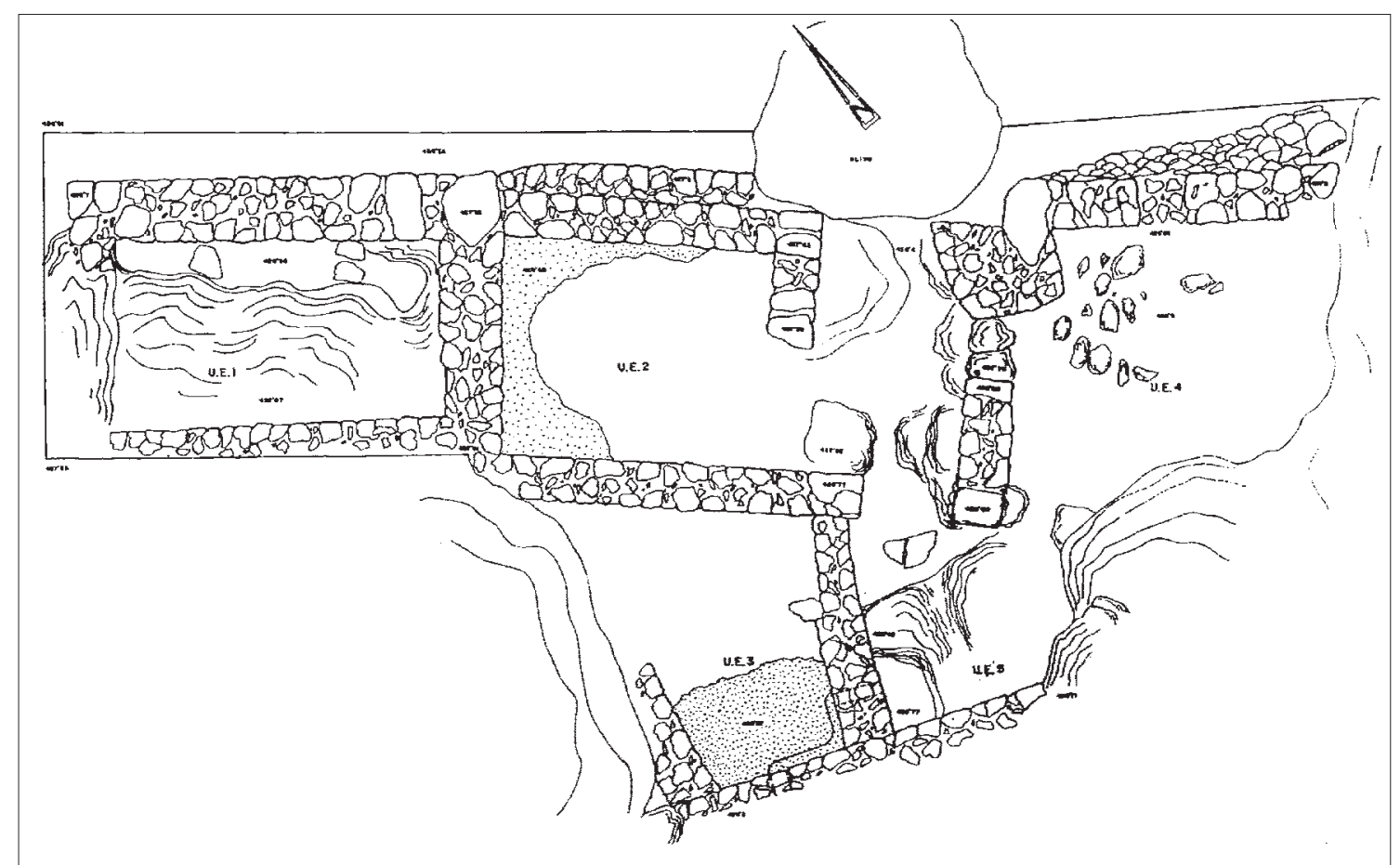

Fig. 5. Corte 6. Planta de una vivienda completa (ACIÉN Y RAMBLA, 1990-91: 292).

4 Se aprobó por dicha Delegación el 25 de abril del 2012, con nº de expediente AA. n 38/12. 
y espacial, generando el correspondiente archivo con la información descriptiva de las piezas divididas en campos específicos. Con respecto al estudio tecnológico, hay que puntualizar que se han abordado aspectos muy concretos que serán aproximativos sin llegar a ser muy precisos a falta de analíticas específicas, pero que nos podrán servir a nivel orientativo, ayudándonos a una aproximación a la cultura que los produjo.

Los aspectos tecnológicos que hemos contemplado son:

- Fabricación a torno, torneta o a mano. Veremos como en la zona objeto de estudio la elaboración a torno es absoluta, sin que hayamos reconocido fragmentos de posible confección a torneta o a mano.

- Tipo de cocción. Existe un porcentaje muy elevado de cocción oxidante lo que produce pastas de tonalidades claras. La cocción de tipo reductora apenas es relevante.

- Desgrasante. Se realiza una apreciación general del tipo de desgrasante y de su tamaño.

El cuarto paso es el análisis de la faceta tipológica que consideramos como un elemento esencial en la que nos hemos basado mayoritariamente para realizar la aproximación a la datación cronológica y a los aspectos culturales asociados con ella.

Los criterios que seguiremos para la clasificación tipológica son los siguientes:

- Estudio de la forma general y de la morfología formal de la pieza.

- Su función.

- Acabado y decoración.

Para la clasificación de todo este material se han utilizado diversas propuestas de clasificación general como son las de J. Zozaya
(ZOZAYA, 1980) y de G. Rosselló (ROSSELLó, 1978). Para el período almohade-nazarí, fundamentalmente, hemos consultado los trabajos de Cavilla Sánchez-Molero (CAVILLA, 2007), la cerámica de cocina de Fernández Navarro (FERNÁNDEZ, 2002), la cerámica nazarí de García Porras (GARCía PORRAS 2001) y el estudio arqueológico de los pozos de Cártama efectuado por Melero García (MELERO, 2012A, 2012B Y 2013). A continuación se procedió a una selección de aquellos fragmentos que se consideraron más representativos (bordes y bases, así como los diferentes tipos de decoración) para realizar su documentación gráfica. El tercer y último paso consistió en su reproducción mediante dibujos cerámicos a escala 1:1 y su posterior digitalización con el programa informático Corel Draw. Esta parte se considera esencial, ya que nos permite generar en archivos informáticos, los diferentes perfiles para su estudio y proponer las seriaciones y evoluciones tipológicas regionales, además de ser un formato apto para su publicación como trabajo científico.

\section{ESTUDIO DEL MATERIAL CERÁMICO}

La subcuenca de río Grande ${ }^{5}$, y buena parte de la provincia de Málaga, adolece hasta el momento de la falta de proyectos de investigación generales que nos permitan conocer el registro arqueológico rural andalusí y por ende la evolución de los tipos cerámicos en la comarca. El único estudio concreto que podemos considerar relevante es el que ha efectuado Melero García en los vertederos medievales de Cártama (MELERO, 2012A Y 2012B).

La justificación de la adscripción cronológica de estos conjuntos que vamos a presentar la basamos en dos aspectos:

1. Contamos con un término post quem con una presencia en los niveles inferiores de cerámica de clara adscripción almohadenazarí. Aunque se han hallado algunos 5 Esta comarca se encuentra en la actual provincia de Málaga abarcando, total o parcialmente, los términos municipales de Yunquera,
Alozaina, Tolox, Casrabonela, Monda, Guaro, Coín y Cártama. 
fragmentos cerámicos elaborados con la técnica de verde-manganeso, su aparición en niveles descontextualizados del hisn, no proporcionan una cronología precisa.

2. Pero, sin embargo, disponemos de un claro término ante quem, especialmente en los cortes relacionados con la alquería (Cortes 4 y 6) en cuyos niveles encontramos una estratigrafía en que coexisten tipologías de tradición almohade-nazarí, con otras de origen cristiano y morisco, estas últimas relacionadas con el siglo XVI. Dicha cronología queda respaldada por la existencia de fuentes escritas en las que se nos informa de cómo la alquería estuvo exclusivamente habitada por moriscos durante todo el siglo XVI, y que fue abandonada en 1569 tras su destrucción por la misma población que la habitaba, no volviéndose a producir un poblamiento intensivo sobre dicho lugar ${ }^{6}$.

En consecuencia, el marco cronológico de que disponemos abarcaría, aproximadamente, desde el siglo XIII hasta finales del siglo XV, para el hisn, y desde mediados del XIV, hasta la década de los sesenta del siglo XVI, para la alquería.

Con respecto a la terminología que vamos a utilizar seguiremos la tradicional de Rosselló por su carácter operativo, lo que nos facilitará la exposición de los resultados. No obstante procederemos a realizar unas tipologías distintas en función de las variantes morfológicas disponibles dentro de cada conjunto estudiado.

Los aspectos del análisis desarrollado abarcarán la técnica de elaboración del producto cerámico (torno o torneta), las diferentes variables tipológicas y los acabados de las mismas (cubierta o ausencia de cubierta vítrea o engobes) como elementos más relevantes para adscribirles una propuesta cronológica a los diversos conjuntos cerámicos.

Para el recuento de las piezas, que nos orientará de su porcentaje dentro de la propia serie o del conjunto total de materiales contabilizados, se han tenido en cuenta los fragmentos que poseen indicios para su adscripción a una tipología determinada. Es decir, se ha dado prioridad a los bordes y bases, al igual que algunos amorfos decorados.

Finalmente, a la hora de la exposición de este trabajo, sólo vamos a tratar la alquería de la Villeta ${ }^{7}$, aunque en el trabajo original se estudiaron los dos sectores del yacimiento. El primero coincidiría con el área excavada del hisn, y el segundo con la zona excavada de la alquería situada debajo del castillo y en la vertiente norte del cerro. Esta diferenciación se produce por el hecho de que en el primer sector hemos detectado un registro arqueológico con una periodización nazarí, con algunas intromisiones de fragmentos cerámicos de tipología castellana que consideramos fruto de una deposición posmedieval. Mientras que en el segundo sector, el de la alquería, también abarcaría el período anterior, pero con un claro nivel perteneciente al siglo XVI, y en los que la influencia material castellana es evidente en el contexto morisco del poblamiento.

\section{LA ALQUERÍA DE LA VILLETA}

Los niveles arqueológicos de este sector coinciden con los Cortes 4 y 6 que se realizaron en la ladera norte, dentro del recinto del albacar y sobre los restos de una alquería que existía por debajo del emplazamiento del hisn.

6 Es revelador el informe que realizó el escribano Bonifacio de Villalabos cuando visitó, en enero de 1572, la "villa bieja” de Monda: “" andube mirando y todas las cassas de la dicha villa bieja estaban caidas, sin puertas ni umbrales ni otra madera ni materiales, salvo algunas texas, y las murallas que zercan la dicha villa assimismo estaban caídas por el suelo [...] dijeron que en la dicha villa abia antes del lebantamiento, hasta nobenta cassas pocas más o menos, e por estar de ningún probecho y en lugar aspero e ynabitable, no se hizo copia particular de ellas..." (URBANO, 1998: 201).

7 La cerámica de la alquería será el objeto fundamental de este trabajo, aunque estableceremos algunas comparaciones estadísticas con los conjuntos cerámicos del hisn que nos ayudaran a comprender la evolución de la cerámica tardonazarí. 
Dichos cortes pertenecen a varias viviendas. El C-4 correspondería con la zona del poblamiento más próxima al albacar, y en ella aparecen parte de dos viviendas separadas por una atarjea. El C-6 se localiza en la zona de la alquería más cercana al hisn y quizá constituiría una vivienda completa.

Se han podido individualizar sesenta y ocho fragmentos reconocibles, trece pertenecientes al C-6, y cincuenta y cinco al C-4, que conservan información para poder ser relacionados con un grupo determinado (Tabla 1). De estos presentan cubierta vítrea o algún tipo de decoración, cuarenta y nueve de ellos que representan el $72 \%$ del total.

Porcentualmente los conjuntos están dominados por la presencia de la cerámica de presentación de alimentos que ocupa el 39,9\% del total (ataifores con un 25\%, platos y escudillas con el $14,7 \%$ ), seguido de los recipientes de exposición al fuego con un porcentaje del $19,11 \%$ (cazuelas y marmitas con un 13,23\% y $5,88 \%$ respectivamente) a continuación los contenedores de líquido/servicio de mesa (18,64\% de jorros/as, jarritos/as), recipientes de usos múltiples (alcadafes con un 8,82\%), servicio de iluminación con un porcentaje del $5,88 \%$, objetos de uso complementario (tapaderas) que también le corresponde el
$5,88 \%$, y finalmente los contenedores para almacenamiento con el 2,94\% del total (orzas).

El tipo de cocción existente es el de ambiente oxidante que proporciona a las pastas tonalidades claras y uniformes.

En general todas las arcillas están depuradas, aunque existen diferentes niveles. Los platos, fragmentos de candiles de píe alto y los cuencos, están elaborados con pastas muy depuradas. Dentro de este grupo podemos también incluir algunas cazuelas con bordes en ala y vedrío melado interior, y las jarritas con recubrimiento vidriado. Dentro de los alcadafes, el único que está bizcochado, posee desgrasantes de pequeño y mediano tamaño. Todas las series han sido elaboradas a torno.

\section{CERÁMICA DE EXPOSICIÓN AL FUEGO}

Serie cazuela. Representan el 69,23\% de la cerámica de exposición al fuego, alcanzando el 13,23\% del conjunto de piezas totales de la alquería, con nueve fragmentos útiles identificados, todos ellos pertenecientes a bordes.

En el Corte 4, diferenciamos la UE-2, UE-3 y la UE-4. Dentro de la UE-2 está el borde 1-H, en la UE-3 distinguimos los fragmentos: 1-A y 1-B.

\begin{tabular}{|c|c|c|c|c|}
\hline \multicolumn{5}{|c|}{ TABLA DE FRECUENCIA DE TIPOS CERÁMICOS } \\
\hline \multirow[b]{2}{*}{ TIPOS } & \multicolumn{2}{|c|}{ HISN DE LA VILLETA } & \multicolumn{2}{|c|}{ ALQUERÍA DE LA VILLETA } \\
\hline & No & $\%$ & No & $\%$ \\
\hline MARMITA & 0 & 0 & 4 & 5,88 \\
\hline CAZUELA & 16 & 23,52 & 9 & 13,23 \\
\hline ATAIFOR & 16 & 23,52 & 17 & 25 \\
\hline ESCUDILLA & 4 & 5,88 & 4 & 5,88 \\
\hline PLATO & 2 & 2,94 & 6 & 8,82 \\
\hline JARRITA/JARRO & 16 & 23,52 & 12 & 17,64 \\
\hline CANDIL & 6 & 8,82 & 4 & 5,88 \\
\hline ALCADAFE & 5 & 7,35 & 6 & 8,82 \\
\hline TINAJA & 2 & 2,94 & 0 & 0 \\
\hline TAPADERA & 1 & 1,28 & 4 & 5,58 \\
\hline ORZA & 0 & 0 & 2 & 2,94 \\
\hline TOTAL & 68 & 100 & 68 & 100 \\
\hline
\end{tabular}

Tabla 1. Estadística porcentual de los tipos cerámicos. 
A la UE-4 corresponden los bordes siguientes; 1-C, 2-A (primera cava) y 2-D. Con respecto al Corte 6 (C-6) solamente existen en la UE-2, con los fragmentos; 1-G, 2-B y 2-C.

Están elaboradas con pastas depuradas, tipo ferruginosa, y desgrasantes de pequeño tamaño. Son frecuentes las huellas exteriores de exposición al fuego. Sin embargo la figura 1-G tiene un acabado tosco y poco cuidado.
Hemos utilizado como elemento diferenciador de estos útiles sus bordes, observándose tres tipos:

-Tipo I. Bordes exvasados que poseen labios alargados en forma de ala recta o ligeramente orientados hacia arriba. Presentan paredes curvas con un total de seis fragmentos (Láms. 1-A, 1-B, 2-A, 2-B, 2-C y 2-D), de los que existe un predominio porcentual
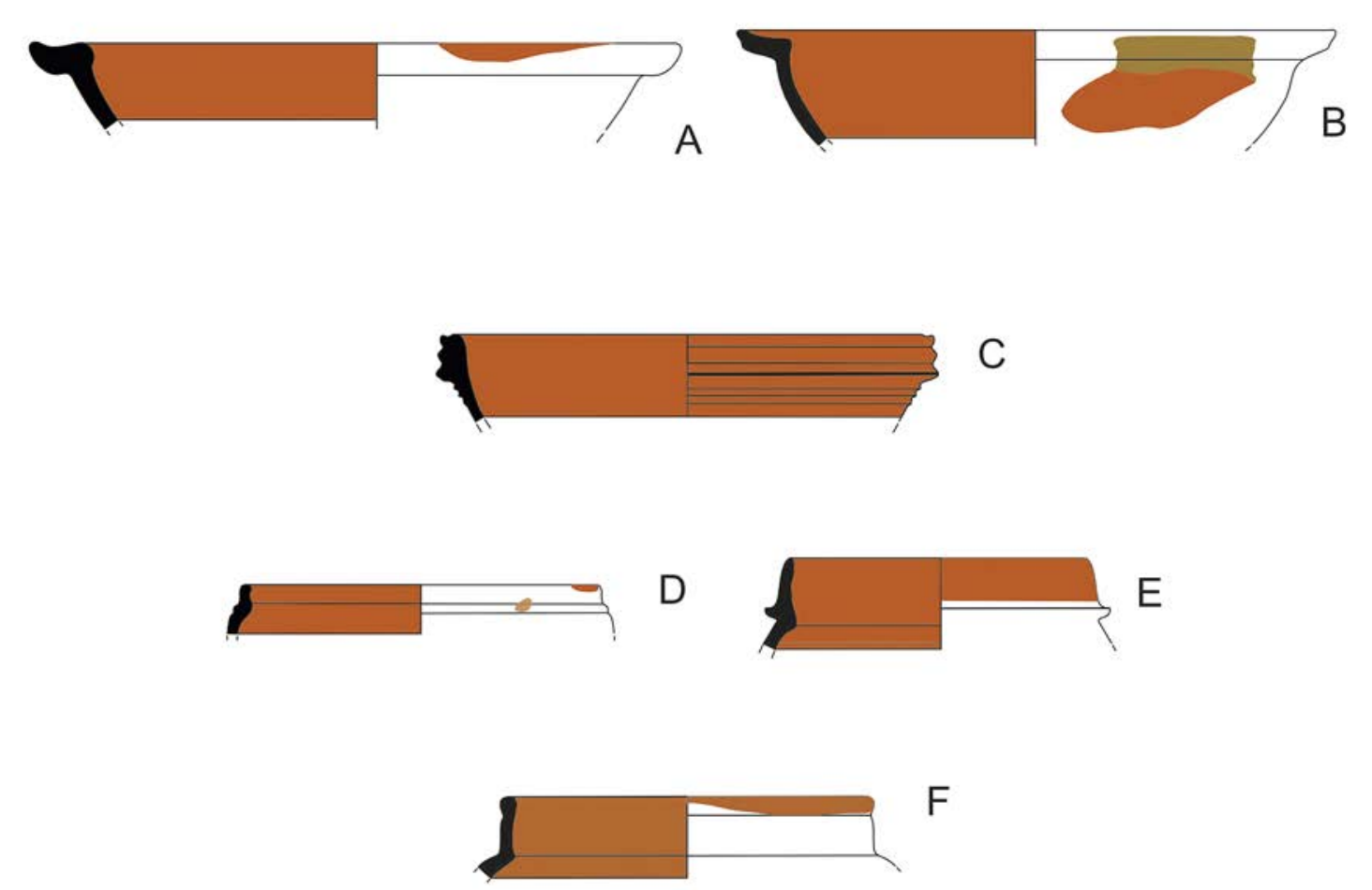

F
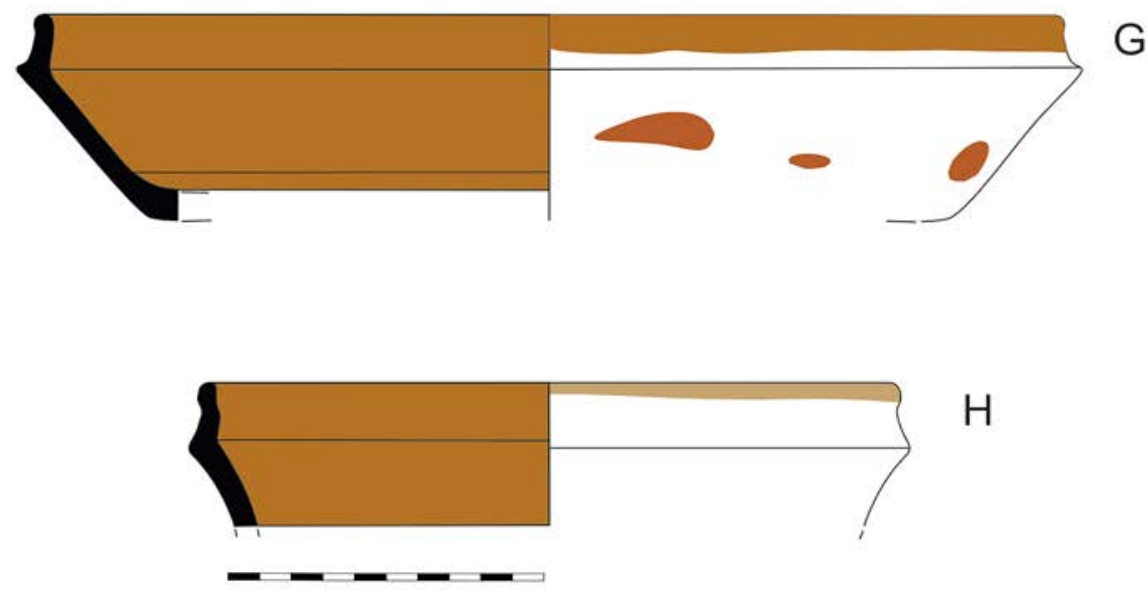

$\mathrm{H}$

Lámina 1 
de cazuelas bizcochadas (cuatro bordes) frente a las de vedrío melado en su interior (dos bordes). Muestran una longitud de labio variable, que puede oscilar entre los cinco centímetros del fragmento 2-A, frente a los dos centímetros del borde 2-B. Estas cazuelas en ala y con vedrío melado interior son ya usuales en los períodos almohade y nazarí, prolongándose su uso hasta el siglo XVI en ámbitos mudéjares y moriscos.

Vemos, al igual que ocurrió en el hisn, como un alto porcentaje de estas cazuelas (el 40\% del total) no poseen ningún tipo de cubierta vítrea para unos utensilios de exposición al fuego en que ya, para el siglo XIII, dicho recubrimiento comenzaba a generalizarse. Sus tipologías siempre han sido similares, con bordes en ala de las que ya poseemos antecedentes en época emiral (ACIÉN et alii, 2003: 13 y 98), almohade (CAVILLA, 2007, Fig. 1 , no IV) y nazarí (MELERO, 2012a, Fig. 13, Tipo 6.1), y que también se continuaron utilizando por la comunidad morisca durante el siglo $X V I$. Es evidente que tenían una función culinaria debido al tiznado que poseían en su parte externa. Planteamos la posibilidad que pudieran ser utilizadas para la preparación de determinados alimentos que no necesitaran líquidos (aceite o agua) y que pudiera dejar impregnado el barro de malos sabores, además de estar expuestas a un fuego envolvente como demuestra el tiznado de la mayoría de la superficie cerámica. Algunos investigadores proponen que una de sus utilidades podría haber sido el horneado del pan (GÓMEZ BECERRA, 1992: 47).

-Tipo II. Borde recto, invasado, moldurado al exterior con una serie de acanaladuras en que destaca un saliente a modo de espolón que tenía la función de sujeción de la tapadera. Sus paredes son divergentes. La única representación existente (Lám.1-C) tiene un vedrío melado interior con chorreones exteriores. Tenemos antecedentes de este último tipo, con características parecidas en la segunda mitad del siglo XIII y principios del XIV (GARCíA PORRAS, 2001, Fig.67 y 68: 518). Sin embargo las tipologías que más se asemejan pertenecen ya al siglo XVI, tratándose de una cerámica de conquista introducida por los cristianos y que, desde nuestro punto de vista, es un signo de aculturación material en las comunidades moriscas donde existía su presencia. Así es usual en excavaciones arqueológicas que se vienen realizando en el casco histórico de Granada (RODRIGUEZ AGUILERA, 2000: 151; y RODRIGUEZ AGUILERA y BORDES, 2001: 17) y en núcleos rurales también ocupados por los castellanos (GARCíA PORRAS, 1995, Fig.2: 255).

-Tipo III. Bordes de tendencia rectilínea, moldura redondeada al exterior y paredes divergentes marcando una carena con pestaña pronunciada que separa el labio de la pared. Las dos figuras relacionadas con este tipo (1-G y 1-H) poseen vedrío melado en su interior con chorreones al exterior. Parece que tiene su origen en la cerámica cristiana de Paterna donde formas similares se han fechado a mediados del siglo XIV (AMIGUES y MESQUIDA, 1993, Fig. 531) y ya en el siglo XVI (MESQUIDA, 1996: 84). Tenemos constancia también de tipologías similares en Almería datadas entre finales del siglo XV y principios del XVI (FLORES y MUÑOZ, 1997: Fig. G y H: 25).

Serie marmita. Representa el 30,76\% de la cerámica de exposición al fuego, alcanzando el 5,88\% del conjunto de piezas totales de la alquería y con cuatro fragmentos útiles identificados, todos ellos pertenecientes a bordes. En el Corte 4 sólo existen piezas relacionadas con el tipo marmita en la UE-3 con los siguientes bordes: 1-E, y 1-F y 2-E. Dentro del Corte 6 y en la UE-2, está el tipo 1-D.

Como corresponde a la mayoría de la cerámica de exposición al fuego poseen pastas depuradas con desgrasantes de pequeño tamaño. La totalidad de los fragmentos tienen huellas de tiznados, tanto al exterior como en el borde interior. Hemos utilizado como elemento diferenciador de estos útiles sus bordes observándose tres tipos:

-Tipo I. Se distinguen por su borde escotado, con labios rectos de terminación redondeada y con paredes convergentes. Son 
muy habituales en el siglo XIV cuando ya el vidriado interior estaba generalizado en estas tipologías (SALADO et alii, 1999, Fig.55: 247). Corresponde con la figura 1-F. La marmita 2-E presenta las mismas características tipológicas, pero carece de recubrimiento melado interior. Esto era habitual a finales del siglo XII y en el primer cuarto del siglo XIII (CAVILLA, 2007, Lám.2: 412 y 445) por lo que le atribuimos un probable origen almohade. También encontramos algunas muestras de estas marmitas bizcochadas en el vertedero medieval de Cártama (MELERO, 2012b, Fig. 2.8: 162) con una cronología que abarca- ría el segundo y tercer cuarto del siglo XIII. Podrían tratarse de tipos residuales, poco representativos.

-Tipo II. Marmita con borde invasado, apuntado, con una protuberancia interna que separa el cuerpo del labio y con moldura externa en forma de espolón que tendría la finalidad de sujetar una tapadera. Sus paredes son convergentes (Lám.1-E). Esta forma parece proceder de la evolución del Tipo I, con un cuello que se va alargando, reborde interno y en algunos casos moldura externa (MALPICA et alii, 2007: 222), formas que alcanzan

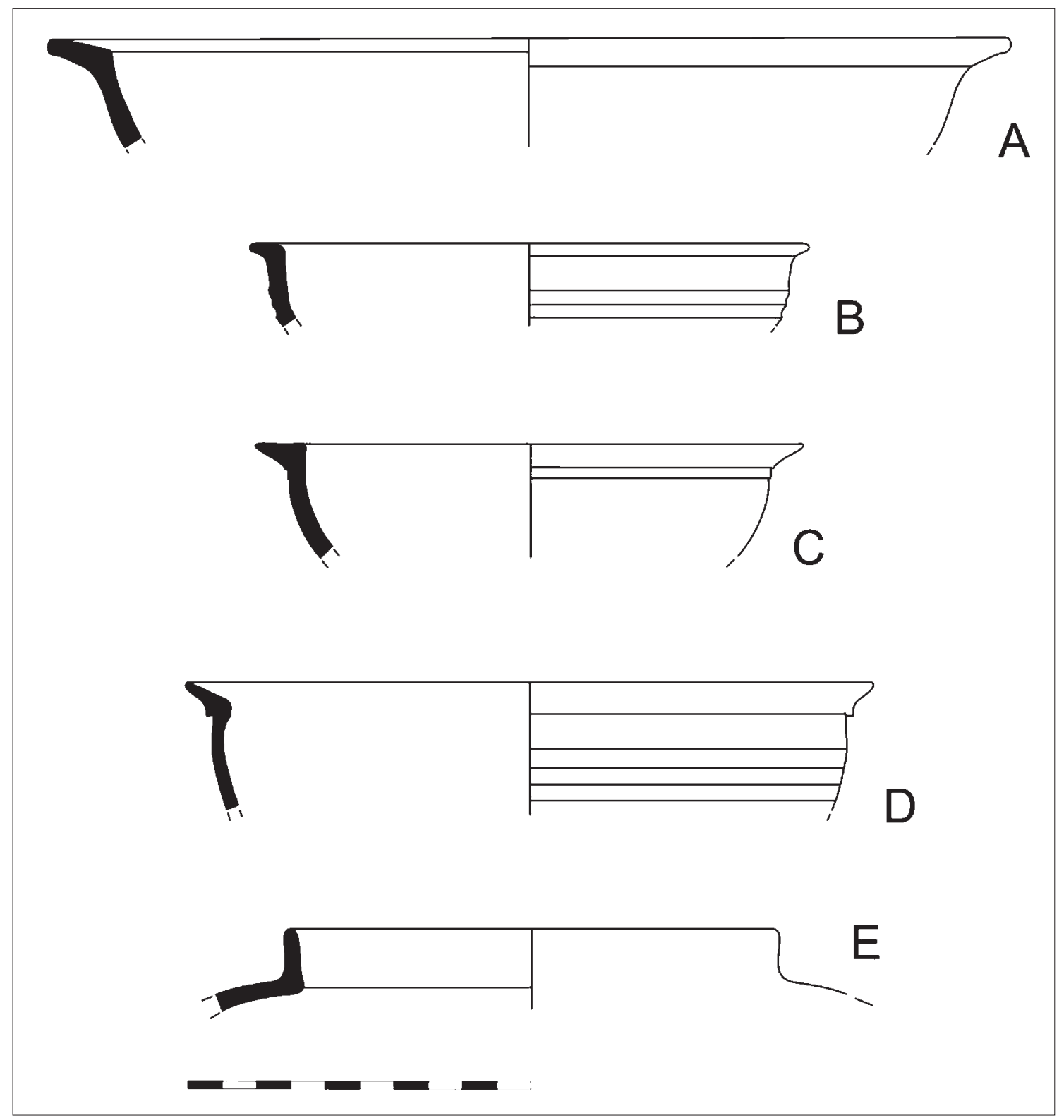

Lámina 2 
un desarrollo notable durante la segunda mitad del siglo XIIII y en la primera mitad del XIV (GARCÍA PORRAS, 2001, Fig. 21 y 22: 495). Sin embargo relacionamos más este modelo con tipos propios del siglo XVI debido al desarrollo tanto de la moldura exterior, como por lo pronunciado de la protuberancia interna. Formas similares también se han documentado en contextos del siglo XVI en el Albaicín granadino con marmitas de cuerpo globulary cuello cilíndrico, protuberancia interior para sujetar la tapadera y con el tipo de cazuela de borde exvasado y resaltes exteriores en el labio. Esta última de clara procedencia cristiana y cuya aparición es contemporánea o posterior a la conquista castellana (RODRIGUEZ AGUILERA Y BORDES, 2001, Lám. 1 y 2: 16-17).

-Tipo III. Borde recto, corto, con terminación redondeada y moldura en su cara interna para sujeción de tapadera, poseyendo vedrío interior (Lám.1-D). Retuerce Velasco la engloba dentro de su subtipo F.02.J y la figura 302, vinculándola con el siglo XIII (RETUERCE, 1998). Pero el subtipo de Retuerce no posee vedrío, por lo que probablemente la tengamos que enmarcar en una cronología más tardía, relacionándola con finales del siglo XIII y principios del XIV, cuando ya es mayoritario el vidriado interior en los artefactos de exposición al juego. Sólo conocemos un precedente con la misma tipología y recubrimiento en niveles superficiales de la alquería de la Torrecilla (ORDÓÑEZ, 2012: 75) a una distancia no superior a diez kilómetros del yacimiento objeto de nuestro estudio y en término municipal de Coín (Málaga).

Vemos como la proporción de marmitas en los ajuares domésticos es de un 5,88\%, frente al 13,23\% de cazuelas para la alquería de la Villeta. Esto, para nuestro punto de vista, es un indicador de que se mantuvieron los porcentajes cazuelas-marmitas similares a los del período nazarí, aunque tipológicamente ya observamos una cierta aculturación material cristiana que se manifiesta en los bordes 1-C, 1-E, 1-G Y 1-H.

\section{CERÁMICA DE PRESENTACIÓN DE ALIMENTOS}

Serie ataifor. Se han identificado un número de diecisiete fragmentos de ataifores, con un porcentaje del $62,96 \%$ con respecto al total de la serie de presentación de alimentos, y del $25 \%$ del total de los fragmentos útiles del la alquería. Las piezas están constituidas por doce bases, cuatro bordes y por un amorfo, de los cuales todos presentan vedrío, predominando los recubrimientos en verde (diez fragmentos), con esmalte estannífero (un fragmento) y recubrimiento en vedrío melado (seis fragmentos). Hay que destacar que todos presentan vedrío sólo en su interior, salvo el borde 3-A que también lo muestra en su exterior, con un recubrimiento en verde esmeralda más diluido.

Dentro del C-4 los diversos fragmentos están incluidos en cuatro Unidades Espaciales (UE). A laUE-2 pertenecen los ataifores: 3-B y 3-D, 3-E, 4-B, 4-C y 4- F . En la UE-3 están incluidos los fragmentos: 3-G, 3-H, 3-I y 3-K. Por último la UE-5-6 está integrada por los siguientes trozos: 3-A, 3-F, 3-J y 4-E.

En el C-6 únicamente consta la UE-2, con un amorfo (Lám.4-F), una base (Lám.3-C) y un borde proveniente de la primera cava, es decir de niveles superficiales (Lám.4-A).

Sus pastas las podemos dividir en dos grupos claramente diferenciados que están relacionados cada uno con un tipo de cobertura y probablemente, con períodos culturales y cronológicos diferentes.

Con pastas de tonalidades claras, depuradas y desgrasantes de tamaño imperceptibles, tenemos la totalidad de los ataifores incluidos en la Lámina-3, salvo el fragmento 3-J con esmalte estannífero. Dicha pasta presenta una composición en láminas muy característica que es común a todos los ataifores con recubrimiento en esmalte estannífero y en óxido de cobre dentro de la Hoya del Guadalhorce (ORDÓÑEZ, 2012: 74).

Parece evidente que había una comunicación fluida entre los diversos asentamientos rurales, y entre estos y los principales núcleos 


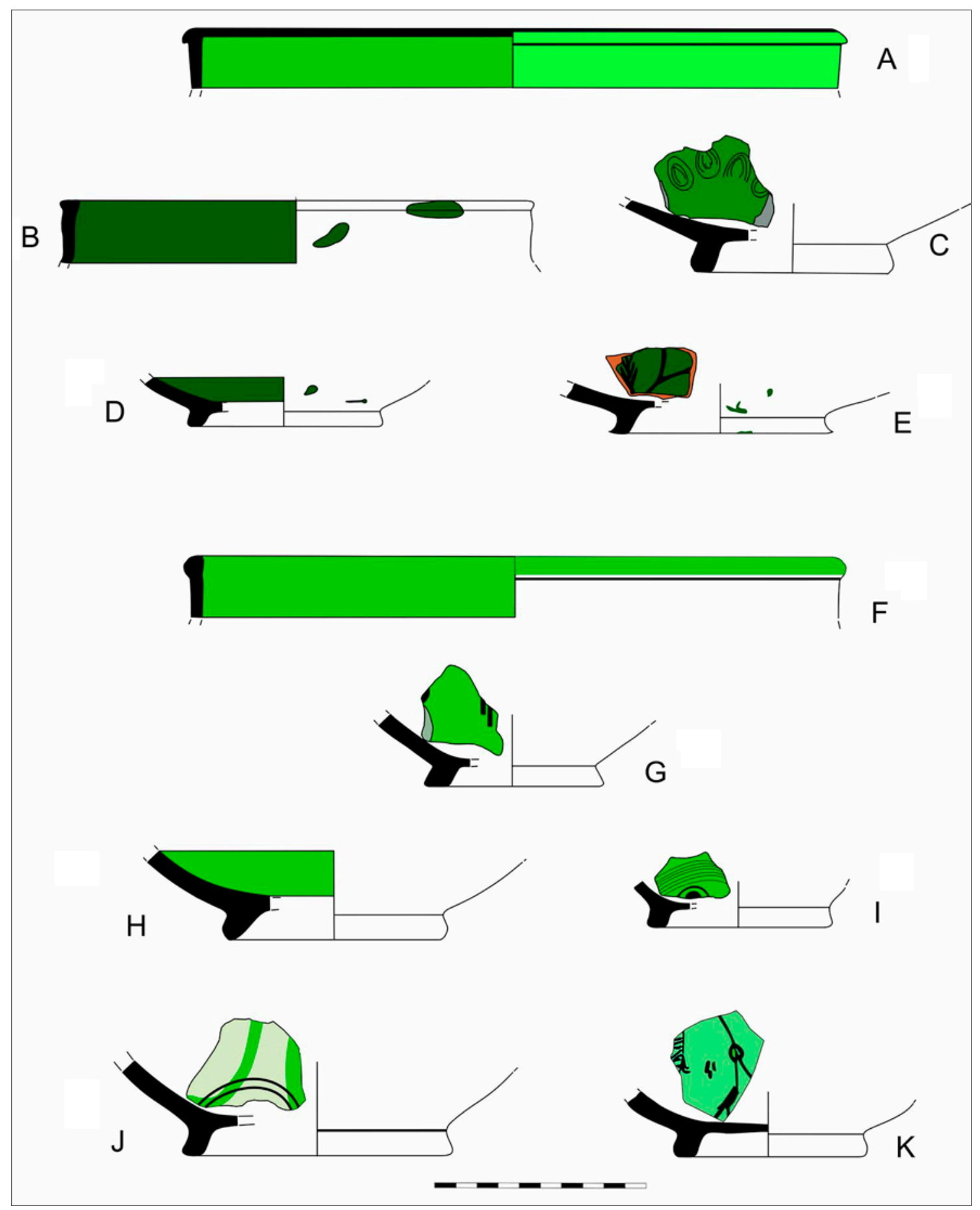

Lámina 3

poblacionales de la comarca como serían Málaga y Dakwan (Coín). La posibilidad de la existencia de talleres que realizaran producciones estandarizadas en estos dos núcleos parece segura, producción que seguirían unos cauces regulares de comercialización que irían desde los talleres cerámicos del arrabal de Fontanella, posiblemente también desde Dakwan, y su distribuirían por toda la subcuenca de río Grande. Ello explicaría el porqué determinadas tipologías de ataifores, marmitas o cazuelas se repiten en la mayoría de los yacimientos con pastas, recubrimientos y decoraciones idénticas. 
Los recubrimientos, como hemos dicho, están basados en la aplicación de óxido de cobre y de esmalte blanco estannífero. La decoración presenta diversas variantes, como el estampillado simple almendrado (Lám.3-C), líneas en óxido de manganeso (Láms.3-E, 3-G y 3-I), bandas en óxido de cobre (Lám.3-J) y decoración en óxido de manganeso con el motivo al-c-afiya en el fragmento de base 3-K.

En cuanto a la tipología de este primer grupo correspondería a la que denominamos "ataifor de perfil quebrado" con repié anulary paredes ligeramente curvadas que dan paso al quiebro y borde de tendencia recta con moldura triangular al exterior.

La aplicación del óxido de cobre comienza a utilizarse en al-Andalus con la técnica del verde manganeso califal, aunque su uso se generaliza en el siglo XIII, en un proceso que va desde el recubrimiento total de la pieza (MELERO, 2012b, Fig.3-A: 161-162), siempre la zona exterior más diluido que la interior, para en el siglo XIV prácticamente desaparecer de la cara exterior ${ }^{8}$. Por lo tanto a estos últimos ataifores podemos adscribirles una cronología que iría desde la segunda mitad del siglo XIII y que incluiría buena parte del siglo XIV (MELERO, 2012a: 35).

Dentro de los ataifores con vedrío verde destaca un fragmento que posee recubrimiento con tonalidades oliváceas y decoración con trazos de óxido de manganeso (Lám.3-E). Se trata de una coloración extraña en época nazarí y que nos remite a los períodos almorávide y almohade. Dado el contexto bajomedieval tardío en que nos movemos podría tratarse de un fragmento residual. También tenemos que tener en cuenta que esta periodización se establece en excavaciones realizadas en Málaga y Cártama, frente a una zona relativamente alejada de la ciudad como sería Monda, por lo que podríamos barajar la posibilidad de que se trataran de recubrimientos que han permanecido en el ámbito rural a través del tiempo con pocos cambios.
El esmalte estannífero con decoración en óxido de cobre (Lám.3-J), podía ser debido a la influencia mudéjar en los ajuares nazaríes (PLEGEZUELO y LAFUENTE, 1995) siendo su presencia habitual en la zona occidental del antiguo obispado de Málaga. Lo encontramos en el Bajo Guadalhorce ya en la segunda mitad del siglo XIII (MELERO, 2012b: 169), prolongándose hasta el siglo XV. Dentro de la provincia de Granada hay algunas muestras en el yacimiento de El Castillejo de los Guájares que aparece en contextos a caballo entre los siglos XIII y XIV (GARCÍA PORRAS, 2001, Fig. 41: 505).

El fragmento 3-C tiene decoración estampillada sobre vedrío verde esmeralda, con motivos foliáceos simples en forma de almendrados que podría corresponder con una cronología que arrancaría de finales del siglo XII, y se prolongaría hasta mediados del siglo XIII (MELERO, 2012c: 123). Consideramos esta pieza como residual y poco significativa en el conjunto, tratándose de un ataifor de evidente tradición almohade, pero no contemporáneo al período objeto de nuestro estudio. Además es el único fragmento con estampillado que se ha hallado en el entorno del hisn.

El ataifor 3-K está recubierto en su cara interna con vedrío en verde muy diluido, presentando la particularidad de que posee la inscripción en árabe al-'afiya (salud) realizada en óxido de manganeso. Ya tenemos constancia de la existencia de este tipo de decoración en ataifores califales. Pero será con los almohades cuando comienza a ser más frecuente. Así Retuerce Velasco ya clasifica algunas de estas inscripciones epigráficas, aunque aparecen en fragmentos con vedrío melado exterior y verde al interior (RETUERCE, 1998, Tipo A.24, Figs. 68 y 69). Creemos que la decoración partiría de un motivo central, probablemente estrellado, desarrollando arcos con alternancias de cartelas, además de palmentas (RUíz GARCíA, 2010:189). Correspondería con una cronología ya plenamente nazarí que podría oscilar entre la segunda mitad del siglo XIV y la primera del XV.

8 Esta pauta de utilización del verde esmeralda en los ataifores es propia de la actual provincia de Málaga. En otras zonas de alAndalus, como por ejemplo el interior de Granada y en Cádiz, el recubrimiento en melado se sigue manteniendo durante el siglo XIII (MELERO, 2012a: 34). 
El segundo grupo de ataifores poseen pastas de tonalidades ferruginosas, con desgrasantes de tamaño muy reducido. Dentro de estas características incluimos todos los fragmentos registrados en la Lámina-4-.

Tienen un vedrío melado en su interior, siendo inusual este tipo de cobertura en la zona occidental del antiguo obispado de Málaga durante los siglos XIV Y XV. Sus antecedentes más próximos los encontramos en los ataifores de los siglos XY XI (MELERO, 2009, Fig. 5, n 1, 2 ,3 y 4: 46 y ACIEN et alii, 1995 :126), que poseían un vedrío melado en toda la superficie de la pieza, decorados con trazos de óxido de manganeso en su interior, repié anular de mayor diámetro y menor alzado que los ataifores tardomedievales, y con una capa de melado sensiblemente más gruesa, características que los diferencian de sus homólogos moriscos del siglo XVI.

En cuanto a la morfología de este segundo grupo, también correspondería a la que denominamos "ataifor de perfil quebrado" con borde recto, repié anulary paredes curvas. Sin embargo, y a diferencia del grupo anterior (ataifores con recubrimiento en verde y esmalte estannífero), los bordes se modifican achatándose y tomando formas indiferenciadas, con escotadura exterior y pestaña pronunciada en el quiebro. Esta es la fisonomía del único borde conservado (Lám.4-A) y que creemos que se podría hacer extensible al resto de los representados en la Lámina-4-.
Estos tipos tienen paralelos en la ciudad de Málaga (SALADO et alii, 1999, Figs. 4 y 10: 240-241) y en Cártama (MELERO, 2012b, Fig. 5-45: 167). Pero en ambos lugares aparecen con recubrimiento en verde esmeralda o en esmalte estannífero y asociadas a una cronología de la segunda mitad del siglo XIV y primera mitad del XV.

Relacionamos estos ataifores con pleno siglo XVI, vinculándolos con la población morisca que habitaba la alquería de la Villeta, y en que las producciones cerámicas tendrían un carácter local. Hay que tener en cuenta que la conquista de Málaga y Coín por los castellanos a finales del siglo XV, supuso la expulsión de la población islámica de ambos núcleos y de la práctica totalidad de sus términos municipales. Parece que se produjo una ruptura con la producción cerámica de tradición islámica en estos centros urbanos ${ }^{9}$ que a diferencia de Granada, donde permaneció un buen número de población mudéjar y morisca ${ }^{10}$, los alfares pasaron a manos de artesanos cristianos ${ }^{11}$. Tenemos dos referencias que podemos asociar con estas tipologías. La primera procede de una reciente actividad arqueológica realizada en Vélez-Málaga (MELERO, 2013) en que han aparecido algunos fragmentos de ataifores o fuentes con su recubrimiento melado interior. La segunda es recogida por Acién que relaciona una serie de ataifores con el siglo XVI y que tienen "...formas mixtas de época mudéjar y morisca, con vidriados melados y semejantes en todo a los cristianos..." (ACIÉN et alii, 1995: 126).

9 Hay evidencias arqueológicas de que el arrabal de Fontanella, en Málaga, fue el principal centro productor cerámico durante los siglos XIII, XIV y XV. Destacamos la excavación que se realizó en el 2003, en el n 2-8 de la calle Chinchilla, con el hallazgo de un importante complejo alfarero datado entre los siglos XII-XV (SALADO, 2003: 74). En Coín sabemos de la existencia de alfares en 1487: "El primer trançe comiença desde la torre y el exido de la ollería, por la parte alta, fasta dar al batan del exido..." (BEN JARANO PÉREZ, 2004: 246). También se constata que durante el siglo XVI era frecuente la presencia de moriscos procedentes de Monda, Guaro y Tolox que trabajaban en Coín, no descartando que los alfares, aunque de propietarios cristianos, utilizaran mano de obra morisca: "Tenían los moriscos de la dicha villa (Monda) en ella, e en sus términos e dezmería de la villa de Coín, e comarca la hacienda de todo géneros que de yuso se dirá e yran declarados, en la qual entran las haciendas que los moriscos, vezinos que fueron de las villas de Tolox e Monda tenían en la dezmería de las dichas villas, e Monda tenían en la dezmería de la dicha villa de Guaro y en la de Coín, toda la qual dicha hacienda está dada y repartida en la dicha población de la dicha villa de Guaro a los nuevos pobladores de ella." (ARCHIVO HISTÓRICO PROVINCIAL DE GRANADA: LIBROS DE POBLACIÓN, LIBRO 6716, 1571, fol. 063-r). Así vemos como en 1554 la ollería de Coín estaba arrendada por el Consejo de Málaga a Juan de Vargas por una renta de "... trescientos maravedies sobre la ollería pagense por San Juan" (ARCHIVO HISTORICO GENERAL DE SIMANCAS, 1554, Leg.0269-0085), aunque no especifica quienes eran los artesanos alfareros.

10 "De todas formas, durante todo el siglo XVI constatamos que el 86\% de los artesanos documentados (Granada) son claramente de filiación islámica, moriscos, mientras que sólo el 14\% son cristianos viejos..." (RODRÍGUEZ AGUILERA y BORDES, 2001: 6)

11 En las Actas Capitulares del Consejo de Málaga -1489-1516- (CRUCESy RUíZ POVEDANO, 2004), menciona a seis olleros y tinajeros: Fernando Martínez (p. 42), Juan López (p. 110), Pedro de Córdoba (p. 225), Juan Gómez (p.309), Juan del Pinar (p. 309) y Antonio Tenorio (p. 584), todos ellos cristianos viejos. También en el Repartimiento de Málaga (BEJARANO ROBLES, 1985: 447-448) de finales del siglo XV, encontramos a tres "maestros de hazer cosas de barro": Alonso Martín Loçano, Alonso Tenorio y Martín García, todos ellos también eran cristianos viejos. 


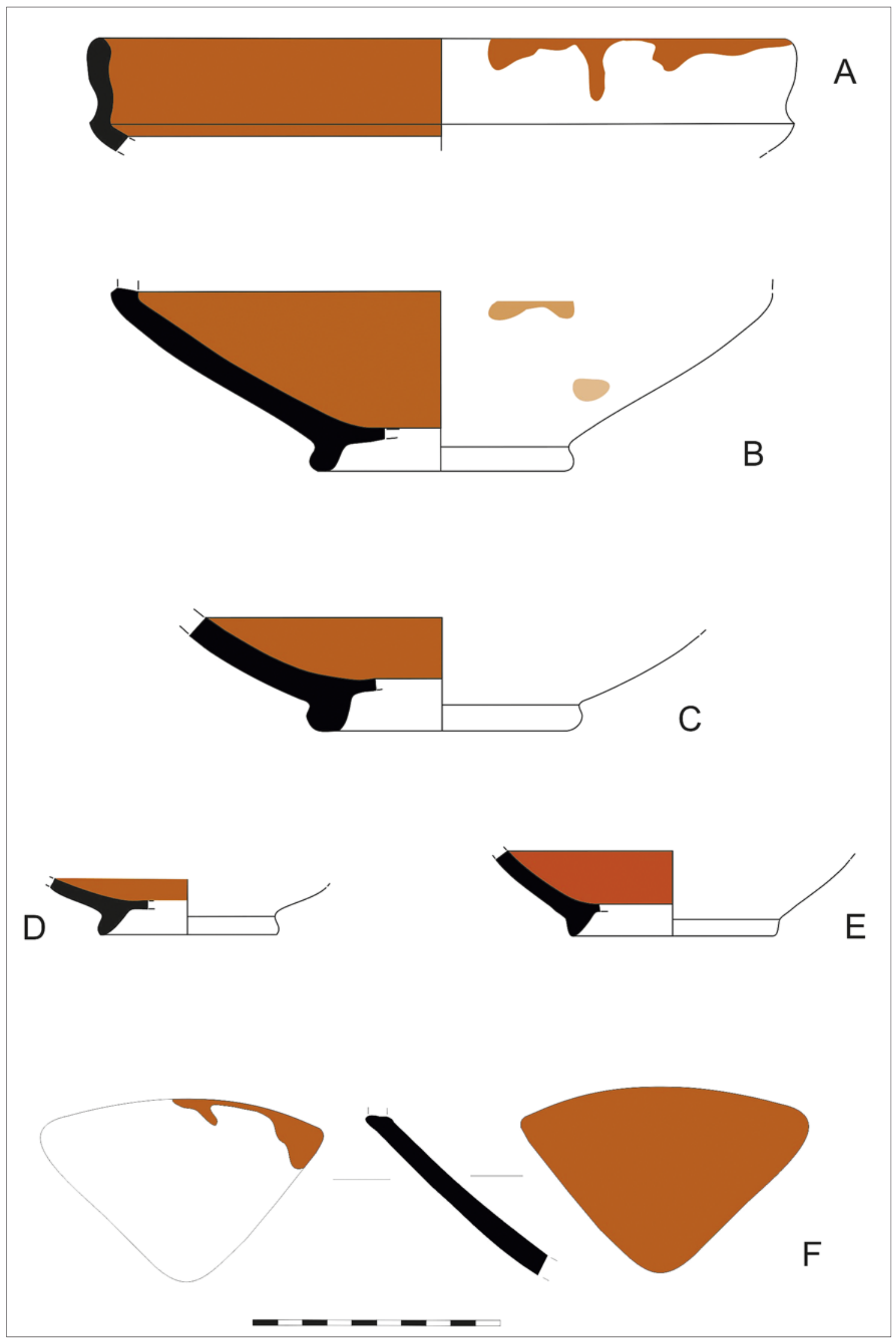

Lámina 4 
Serie plato. Se han contabilizado seis fragmentos de bordes pertenecientes a la "serie plato". Representan el 22,22\% del total de la serie de presentación de alimentos y el $8,82 \%$ del total de los fragmentos de la alquería.

Por Unidades Espaciales (UE) los fragmentos del C-4, pertenecientes a la UE-1, son 5-C y
5-D. Asociados a la UE-2 están las piezas 5-E y 5-F. Dentro del C-6 está la UE-2 con los bordes 5-A y 5-B.

Sus pastas son de tonalidades rojizas y muy depuradas, con desgrasantes bastante pequeños apenas perceptibles.

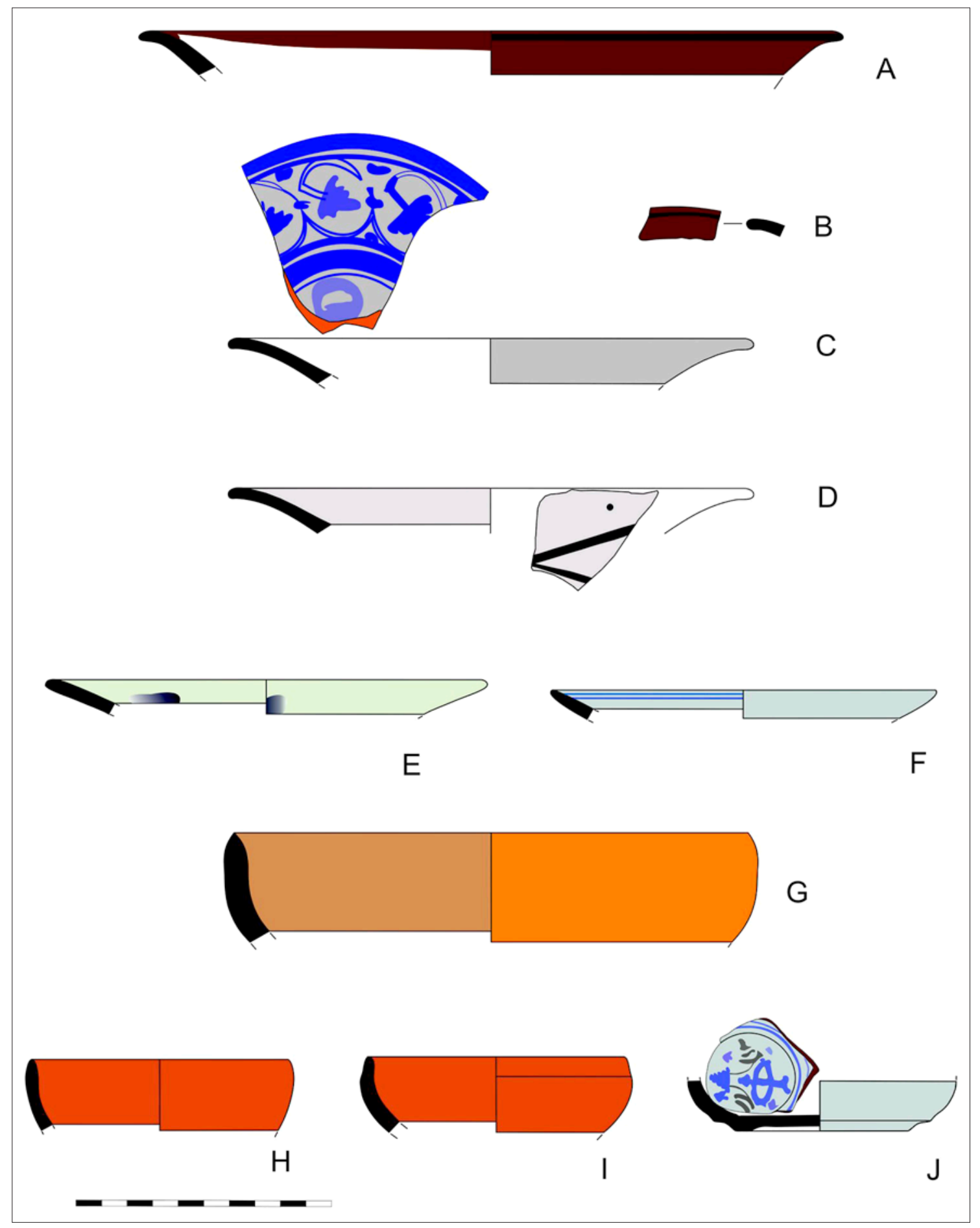

Lámina 5 
Se trata de formas con paredes divergentes y bordes exvasados en que podemos diferenciar dos tipologías distintas:

- Bordes rectilíneos en forma de alay terminación redondeada (Láms.5-A, 5-B, 5-C y 5-D).

- Bordes indiferenciados, también con puntas redondeadas (Láms.5-E y 5-F).

En relación con sus recubrimientos distinguimos básicamente dos tipos; los de cubierta en esmalte estannífero tanto en su anverso como en su reverso, y los que poseen un vedrío melado obscuro sólo en su interior con goterones exteriores.

Al primer grupo pertenecen los fragmentos 5-C, 5-D, 5-E y 5-F. El primero de ellos (Lám.5-C) posee la cubierta estannífera en toda su superficie. La decoración está en la cara interna con trazos en azul y motivos vegetales distribuidos en un sistema radial con trazado cuidado y sin excesivos recargamientos. Desde nuestro punto de vista se trataría de loza azul, manufacturada en Manises, probablemente en el siglo XV (COLL, 2009: 77). Aunque la producción de Manises estaba ya estandarizada en los siglos XIV y XV, pensamos que se podría tratar de cerámica de lujo dado el contexto rural marginal del entorno de la alquería de la Villeta. Los fragmentos de los platos 5-D y 5-E están decorados con franjas de óxido de manganeso, el primero sólo en su cara exterior, mientras que el segundo tanto en su anverso como en su reverso. Hay que destacar la existencia de un orificio en el fragmento 5-D con la probable finalidad de suspenderlo de la pared, lo que nos puede indicar una función decorativa. El borde 5-F tiene dos bandas horizontales ornamentales en azul en el anverso de la pieza.

En el segundo grupo están incluidos los fragmentos 5-A y 5-B, sin ningún tipo de decoración, salvo el recubrimiento interior en vedrío melado obscuro. Destacar el gran tamaño del primer plato con treinta y dos centímetros de diámetro. Estas dimensiones lo acercan más a una vasija de exposición de alimentos para un servicio de mesa comunal, que a un plato de presentación de alimentos individualizado. También podría tratarse de una pieza ornamental.

Cronológicamente, probablemente, pertenezcan a finales del siglo XV y al siglo XVI, cuando ya la presión castellana era notoria en estas alquerías rurales, rodeadas de villas habitadas exclusivamente por cristianos viejos y lejos de los núcleos importantes de población morisca.

Serie escudilla. Existen un total de cuatro fragmentos de bordes pertenecientes a esta tipología, que ocupan un porcentaje del $14,81 \%$ con respecto a la serie de presentación de alimentos, y un 5,58\% del total de las piezas cerámicas.

Por Unidades Espaciales (UE), están divididos, para el C-6, en un fragmento perteneciente a la UE-2 y que procede de la primera cava (Lám.5-H); y para el C-4 en tres fragmentos distribuidos entre las UE-1 (Lám.5-I), UE-2 (Lám.5-J) y UE-3 (Lám.5-G).

Sus pastas son muy depuradas, con variantes en su composición, siendo de tonalidades claras para la figura 5-J y de color rojizo para las figuras 5-G, 5-H y 5-I.

En cuanto a sus tipologías son similares en la totalidad de las escudillas, con paredes ligeramente convergentes hemisféricas, bordes indiferenciados, invasados y terminados en punta. La figura 5-I presenta la particularidad de un estrechamiento pronunciado en la parte superior del borde, junto con una mayor tendencia a la convergencia de este. El fragmento 5-J es la única base clasificada, poseyendo ripié anular y escotadura inferior junto a la base.

Su funcionalidad, como recipiente para el consumo individualizado de alimentos, hay que matizarla. Parece evidente que las escudillas 5-H y 5-I sí tendrían esa finalidad dado su tamaño (12 cm de boca en ambas). Sin embargo no lo entendemos así para el fragmento de base 5-J del estilo decorativo Isabela Polychrome que podría tener más una finalidad decorativa o como vajilla de lujo. Tampoco parece que fuera esta la función del 
fragmento de borde 5-G dado su tamaño, veinticuatro centímetros, englobándolo dentro de lo que denominaríamos como "fuentes", en que se presentaría los alimentos en la mesa para su posterior servicio en cuencos o platos de menor tamaño o incluso, siguiendo la tradición islámica, como servicio de mesa comunal.

Los tres fragmentos de bordes poseen un melado que cubre la totalidad de la pieza (Láms.5-G, 5-H y 5-I). El único trozo de base que poseemos (Lám.5-J) está revestido de esmalte estannífero en toda su superficie, con decoración interior en óxido de cobalto y óxido de manganeso de tonalidades negras y moradas. Es el estilo decorativo llamado Isabela Polychrome, procede de los talleres sevillanos del siglo XVI, y tuvo una gran difusión en las colonias americanas españolas durante dicho siglo. El interés de esta última pieza estriba en que tiene una cronología muy concreta que iría desde 1490 hasta 1580 (PLEGUEZUELO, 1992: 18), y que por lo tanto nos sirve como fósil-guía para clasificar el único nivel existente en la alquería.

Tanto platos como escudillas son tipologías que podrían se indicadores de una aculturación material cristiana que se prolongaría por los períodos tardonazarí, mudéjar y morisCO (MALPICA, 1999: 34). Tampoco podemos descartar una evolución propia de determinados artefactos cerámicos, como es el caso de los ataifores, con una reducción de sus tamaños que los aproximaría en funcionalidad y en forma a las escudillas cristianas.

\section{CERÁMICA DE SERVICIO DE MESA}

Serie jarrita-jarro. Se trata de recipientes de mediano y pequeño tamaña que se utilizaron para la contención de líquidos, generalmente en el servicio de mesa. Tampoco descartamos que algunos de estos contenedores sirvieran también para el almacenaje de determinados productos alimenticios sólidos.

Es uno de los grupos más comunes en la cultura andalusí y que debido a su carácter práctico ha sufrido pocas modificaciones tipológicas en el tiempo. Nos tendremos que basar en su decoración y/o recubrimiento como referente que nos podrán servir, junto a la difusa estratigrafía, de aproximación a la hora de adscribirlos a una cronología determinada.

Se han identificados un total de doce fragmentos pertenecientes a este grupo, todos ellos incluidos en el C-4, de los que sólo se han representado en lámina ocho, priorizando el interés tipológico de las piezas. Suponen el $100 \%$ del total de la serie de servicio de mesa, y el 17,64\% de las muestras halladas en la alquería.

Por Unidades Espaciales (UE) se han contabilizado cuatro fragmentos de la UE-2 (Láms.6C, 6-E, 6-G y 6-H), y ocho de la UE-3, (Láms.6-A, 6-B, 6-D y 6-F).

Existe un predomino de los bordes con un total de seis muestras, frente a dos de bases.

Las arcillas suelen estar muy depuradas con desgrasantes imperceptibles. Se aprecia una excepción en la base 6-E que posee un barro poco depurado, presentando gruesos desgrasantes y constantes oquedades en su interior.

En cuanto a las variantes formales identificadas, las clasificaremos tipológicamente en relación con sus cuellos:

- Tipo 1. Cuellos exvasados con bordes que están moldurados al exterior, bien formando una protuberancia redondeada (Láms.6-B, 6-C y 6-D), o con terminación lineal e indefinida (Lám.6-A).

- Tipo 2. Cuello recto y borde exvasado al exterior con sección triangular (Lám.6-F).

- Tipo 3. Cuello recto, con borde formando una protuberancia al interior de forma redondeada (Lám.6-H).

En relación con las dos bases existentes, la diferencia básica entre ellas es que el fragmento 6-E posee repié, mientras que el 6-G tiene su superficie horizontal. 


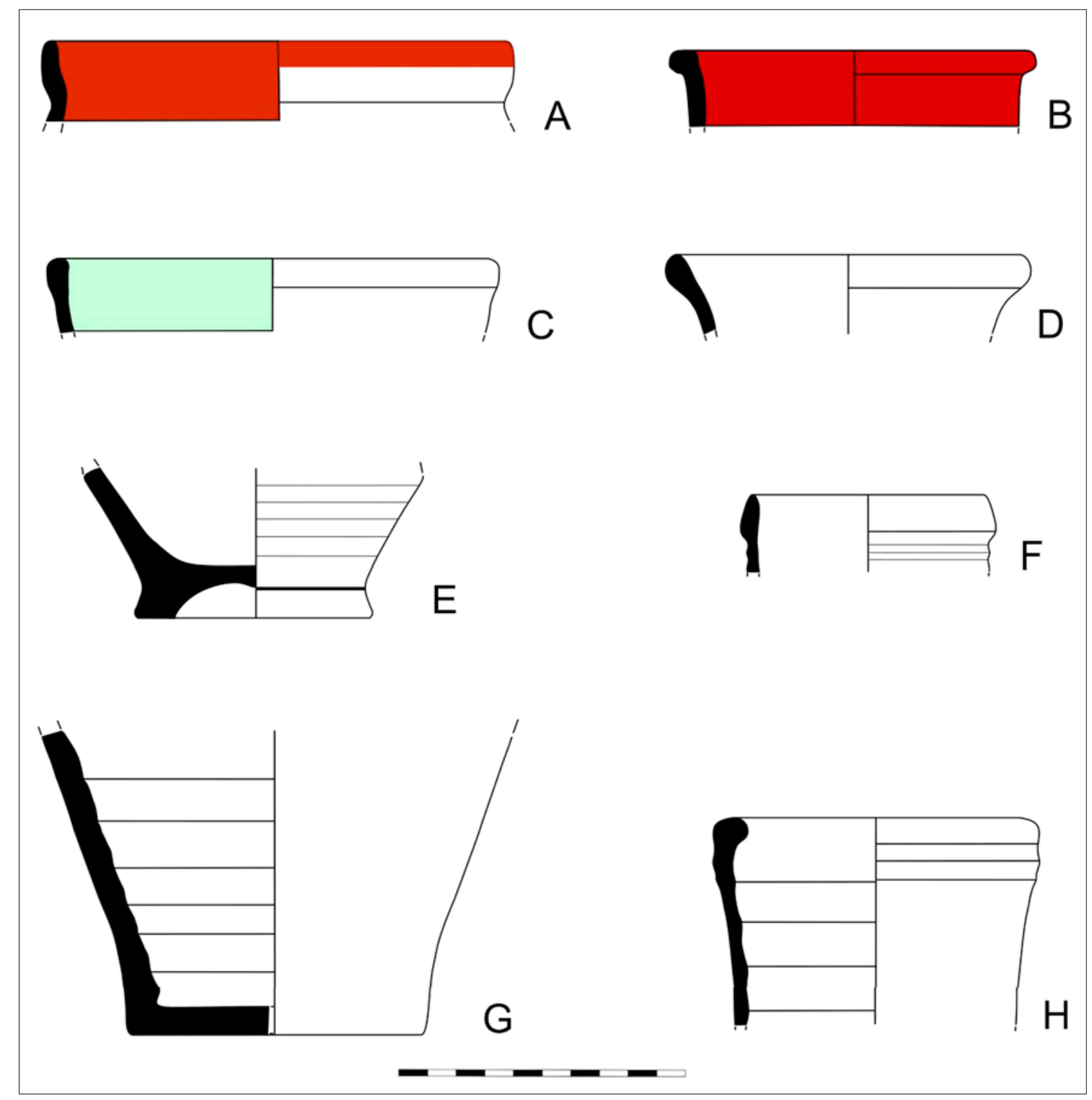

Lámina 6

Las piezas con recubrimiento son minoritarias con tres muestras, frente a cinco bizcochadas. El fragmento 6-B tiene vedrío melado en toda la superficie de la pieza, mientras que el 6-A sólo lo posee al interior y en una franja que cubre el borde exterior. El borde 6 -C también tiene vidriado en azul diluido en su cara interna, recubrimiento que será habitual en el período nazarí.

Aunque la mayoría de las formas no presentan rasgos diferenciadores para poder adscribirlas a un período cronológico concreto, serán fundamentalmente, los recubrimientos los que nos lleven a relacionarlas con niveles bajomedievales.

El fragmento 6-F tiene analogías en la ciudad de Málaga (SALADO et alii, 1999, Fig. 26:244) con una propuesta cronológica dentro del siglo $X V$. Se trata de una tipología que, al igual que la aparecida en el hisn de la Villeta, no tiene ningún tipo de recubrimiento.

El tipo 6-B pertenece a una morfología de recipientes que tienen su origen en jarritos del siglo XII y que serán habituales en contextos de los siglos XIII y XIV (MELERO, 2012a, Tipo 2: 63), 
en que ya el vedrío melado total o parcial era habitual tanto en candiles de pie alto, como en jarros y jarritas. La figura 6-C posee este tipo de vedrío convirtiéndose en un buen referente cronológico del período nazarí pleno.

\section{CERÁMICA DE SERVICIO DE ILUMINACIÓN}

Serie candil. Se han identificado cuatro fragmentos relacionados con esta serie. Tres pertenecen a paternas, y uno a un fuste. Todos ellos se vinculan con el tipo de candil denominado de "pie alto".

Suponen el $100 \%$ de series de servicios de iluminación, y el 5,88\% del total de fragmentos útiles hallados en la alquería.

Los cuatro fragmentos pertenecen al C-4, y dentro de este a las Unidades Espaciales (UE) siguientes: tres se incluyen en la UE-3 (Lám.7-A, 7-B y 7-D), frente a uno que está en la UE-5-6 (Lám.7-C).

Las pastas son muy depuradas y con desgrasantes prácticamente imperceptibles.

En relación con las variedades de cubierta y decoración distinguimos dos tipos:

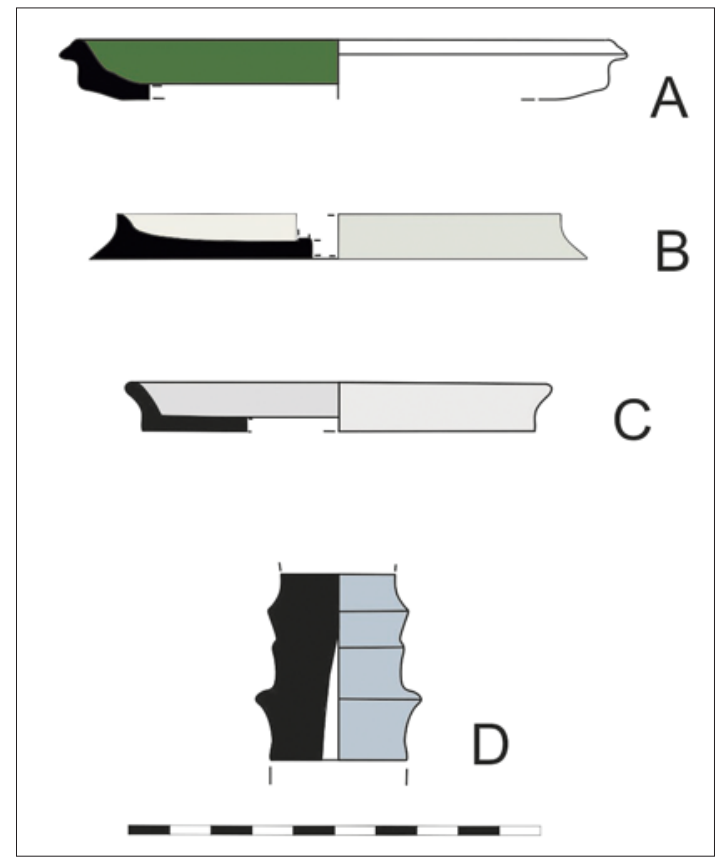

Lámina 7
- Cubrimiento con vedrío verde esmeralda en su cara interna (Lám.7-A).

- Cubierta en esmalte estannífero en la totalidad de la pieza (Láms.7-B y 7-C).

- Vedrío en azul claro, que probablemente derivara de loza azul-dorada en la cual se pudo producir un proceso de degradación que la fue diluyendo (Lám.7-D).

En cuanto a las tipologías de sus bordes destacamos dos formas diferentes:

- Borde vertical con pestaña horizontal saliente a modo de espolón (Lám.7-B).

- Borde exvasado con labio saliente en forma triangular (Lám.7-A). Borde con punta redondeada y espolón moldurado (Lám.7-C). El fragmento de fuste es de los denominados de "estrías" por poseer tres molduras salientes horizontales.

La tipología de los candiles van evolucionando y ya, a finales del período almohade, el candil de pie alto va sustituyendo paulatinamente al de piquera, implantándose de forma generalizada en la etapa nazarí (MALPICA et alii, 2007: 248) y prolongándose por todo el siglo XVI.

Dentro de los recubrimientos el verde esmeralda comienza a aparecer, para la actual Hoya de Málaga, en el período almohade y se generaliza durante el siglo XIV (MELERO, 2012a: 96). El esmalte blanco estannífero se impone en los siglos XIV y XV (SALADO et alii, 1999: 73y 76), y es un claro indicador del período nazarí. Igual ocurre con el vidriado en azul diluido procedente de la loza azul-dorada con una cronología adscrita al siglo XV (MELERO, 2012a: 96).

\section{CERÁMICA DE USOS MÚLTIPLES}

Serie alcadafe. Hemos contabilizado seis fragmentos relacionados con esta serie. Todos ellos pertenecen a bordes.

Porcentualmente suponen el $100 \%$ deseries de usos múltiples, y el 8,82\% del total de fragmentosútiles hallados en la alquería de la Villeta. 
Su presencia es exclusiva del C-4. Por Unidades Espaciales (UE) destacan tres bordes que se incluyen en la UE-5-6 (Láms.8-B, 8-C, 8-D, 8-E y 8-F), y uno dentro de la UE-3 (Lám.8-A).

Las pastas están depuradas, con la presencia de desgrasantes de tamaño medio y pequeño.
Posee un cuerpo con forma troncocónica invertida, con bordes exvasados, redondeados, que presentan dos tipos diferentes:

- Bordes caídos al exterior representados por los fragmentos 8-A, 8-D, 8-E y 8-F.

- Bordes moldurados también al exterior que incluye las piezas 8-B Y 8-C.

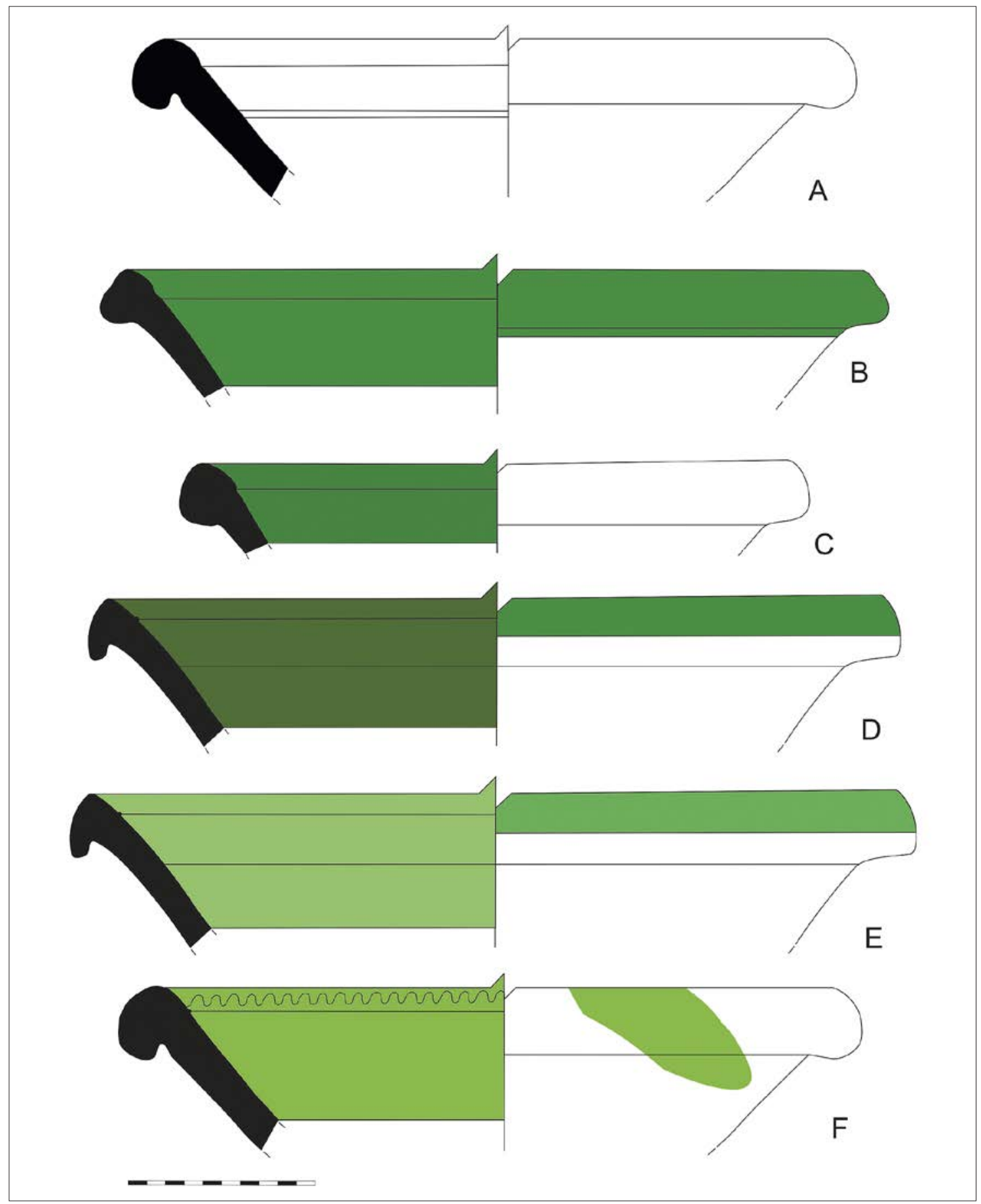

Lámina 8 
De los seis bordes, cinco presentan vedrío en verde. El fragmento 8-B tiene recubrimiento en verde esmeralda en el interior y borde exterior. El borde 8-C sólo esta vidriado con verde esmeralda en su interior. Los fragmentos 8-D, 8-E, 8-F también poseen, respectivamente, vedrío en verde oliva, verde claro diluido y verde claro.

Si relacionamos "la serie alcadafe" de la alquería con los catalogados en el hisn, vemos como a nivel tipológico son muy semejantes ya que ambos grupos poseen labios moldurados al exterior redondeados, o moldurados y caídos. La diferencia más evidente estriba en que cinco de los seis fragmentos poseen vedrío en su cara interna, mientras que los del hisn están bizcochados en su totalidad. Estos recubrimientos están bien registrados en los pozos de Cártama (MELERO, 2012b: 64), dentro del Horizonte III y con una cronología que se relaciona con los siglos XIV y XV, teniendo en cuenta que siempre coinciden con vedrío en verde esmeralda o verde turquesa, diferenciándose claramente de los fragmentos 8-D, 8-E y 8-F en que el verde es mucho más claro y con unas tonalidades brillantes. Además, estos tres últimos tipos presentan también una moldura (saliente) por debajo del borde interior que les diferencian de la muesca interior (entrante) localizadas también por debajo del borde interior y representado en las piezas 8-A, 8-B y 8-C. No hemos encontrado apenas referencias precisas en la literatura científica con relación a los tipos que poseen esta muesca. Melero García los vincula con los alcadafes de la etapa bajomedieval (MELERO, 2012a: 99 y 100). También son muy frecuentes estos artefactos en niveles superficiales de la mayoría de las pequeñas alquerías de la subcuenca de río Grande y que se asocian con los períodos tardoalmohade y nazarí (ORDÓÑEZ, 2012: 74-84). También son escasas las similitudes, en la literatura científica, relacionadas con los alcadafes con moldura interior y vedrío en verde claro ${ }^{12}$ que para nuestro punto de vista se tratan de tipos claramente cristianos y ya dentro del siglo XVI ${ }^{13}$.

\section{OBJETOS DE USO COMPLEMENTARIO}

Serie tapadera. Contamos con cuatro fragmentos que asociamos con esta serie.

Porcentualmente ocupan el $100 \%$ de la "serie tapadera", y el 5,88 \% del total de todos los fragmentos útiles hallados en la alquería.

Están integradas dentro de los C-4 y C-6. En el primer corte se encuentran los fragmentos 9-A (UE-1), 9-B (UE-3) y 9-D (UE-5-6). Dentro del C-6 se sitúa la tapadera 9-C, esta última ubicada en un contexto superficial.

Las arcillas están en general depuradas, salvo el fragmento 9-C con pasta poco decantada y cocción reductora (el único fragmento de la alquería que posee este tipo de cocción).

Estos cubrimientos siguen un mismo modelo tipológico con paredes divergentes y bordes bífidos. El fragmento más completo (Lám.1-B) posee un quiebro que contornea la tapadera y que nos proporciona un fondo aproximado de $11 \mathrm{~cm}$.

Están bizcochadas, es decir no poseen ningún tipo de recubrimiento ni decoración. Este aspecto, junto con sus dimensiones, con una media de diámetro de $23 \mathrm{~cm}$, nos permite relacionarlas con tapaderas de cazuelas, y en concreto con las tipologías que tradicionalmente han permanecido bizcochadas (Láms.2-A y 2-B) y que coinciden con diámetros similares a las de dichas tapaderas.

En cuanto a la forma encontramos paralelos con tipos de los períodos almohade y nazarí, pero a diferencia de las halladas en la alquería de la Villeta, dichas tapaderas están siempre decoradas o cubiertas de vedrío. Esto

12 En el estudio de la cerámica del castillo de Lanjarón (S. XVI), Lentisco Navarro ya hace alusión a un cambio en las tonalidades de los diversos vidriados y a su asociación con series concretas (LENTISCO, 2008: 151)

13 En diversas excavaciones realizadas en la calle Candiota (Granada) se han documentado diversos fragmentos de lebrillos con moldura interior y vedrio en verde. Se relacionan con niveles pertenecientes al siglo XVII. (RODRÍGUEZ AGUILERA et alii, 2011: 41, 127 y 125) 

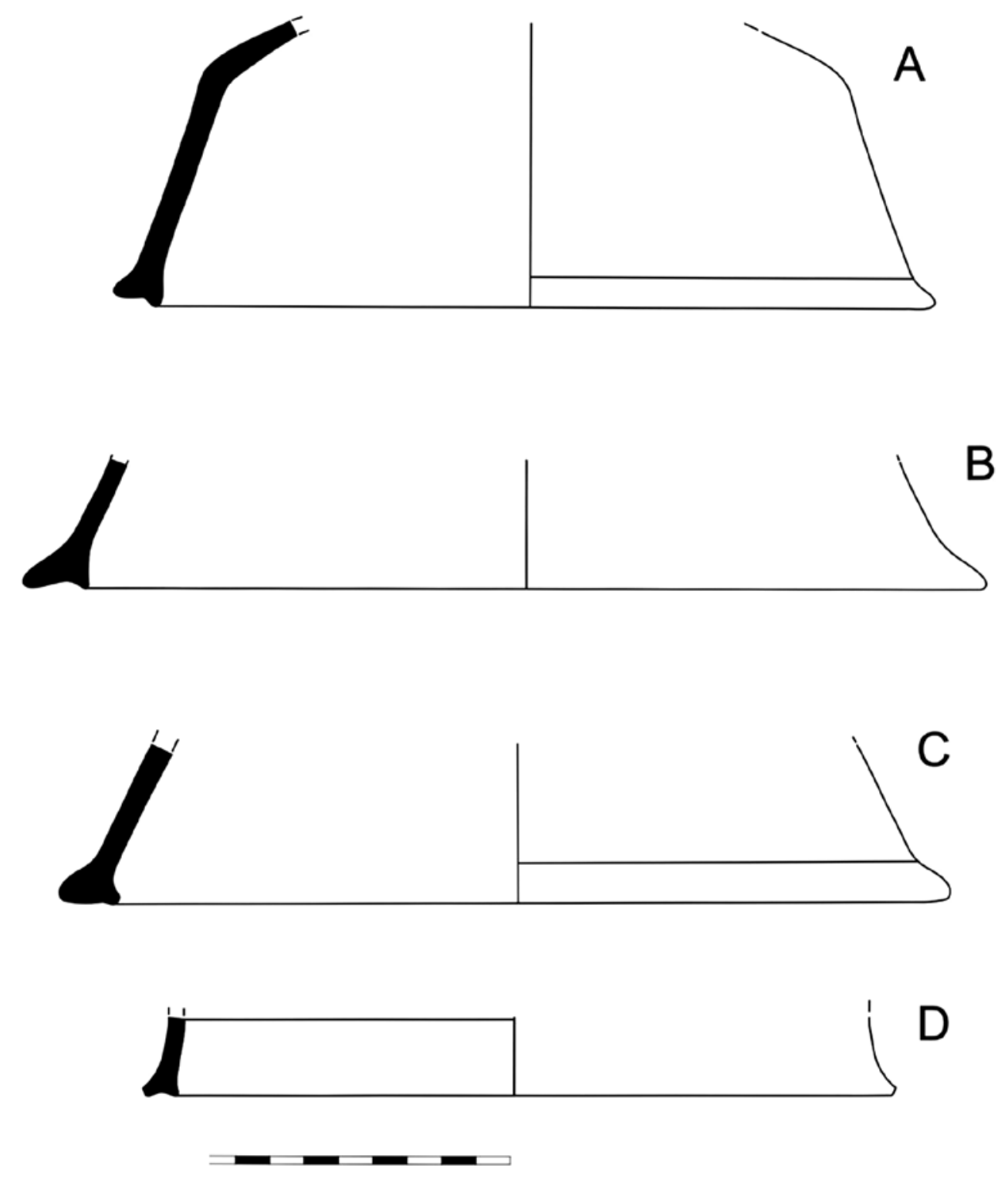

Lámina 9

nos hace pensar en la posibilidad de que la preparación de alimentos en estas cazuelas se realizara en espacios confinados, como podían ser hornos, o con combustiones en que el artefacto estuviera cubierto parcialmente por el combustible. Dicha hipótesis también viene reforzada por la gran cantidad de tizne exterior que aparece en la mayoría de la superficie de los fragmentos hallados. Esta última característica nos hizo barajar la posibilidad de que se trataran de grandes cazuelas. Sin embargo dada su fisonomía, la ausencia de tizne en lo que tendría que ser la base de la cazuela, y la falta de paralelos tipológicos, nos han hecho desistir de esta posibilidad.

\section{CONTENEDORES PARA TRANSPORTE $Y$ ALMACENAJE}

Serie orza. Se han identificado dos fragmentos relacionados con esta serie. El primero (Lám.10-A) se trata de una vasija prácticamente entera. El segundo (Lám.11-A) pertenece a una base. 

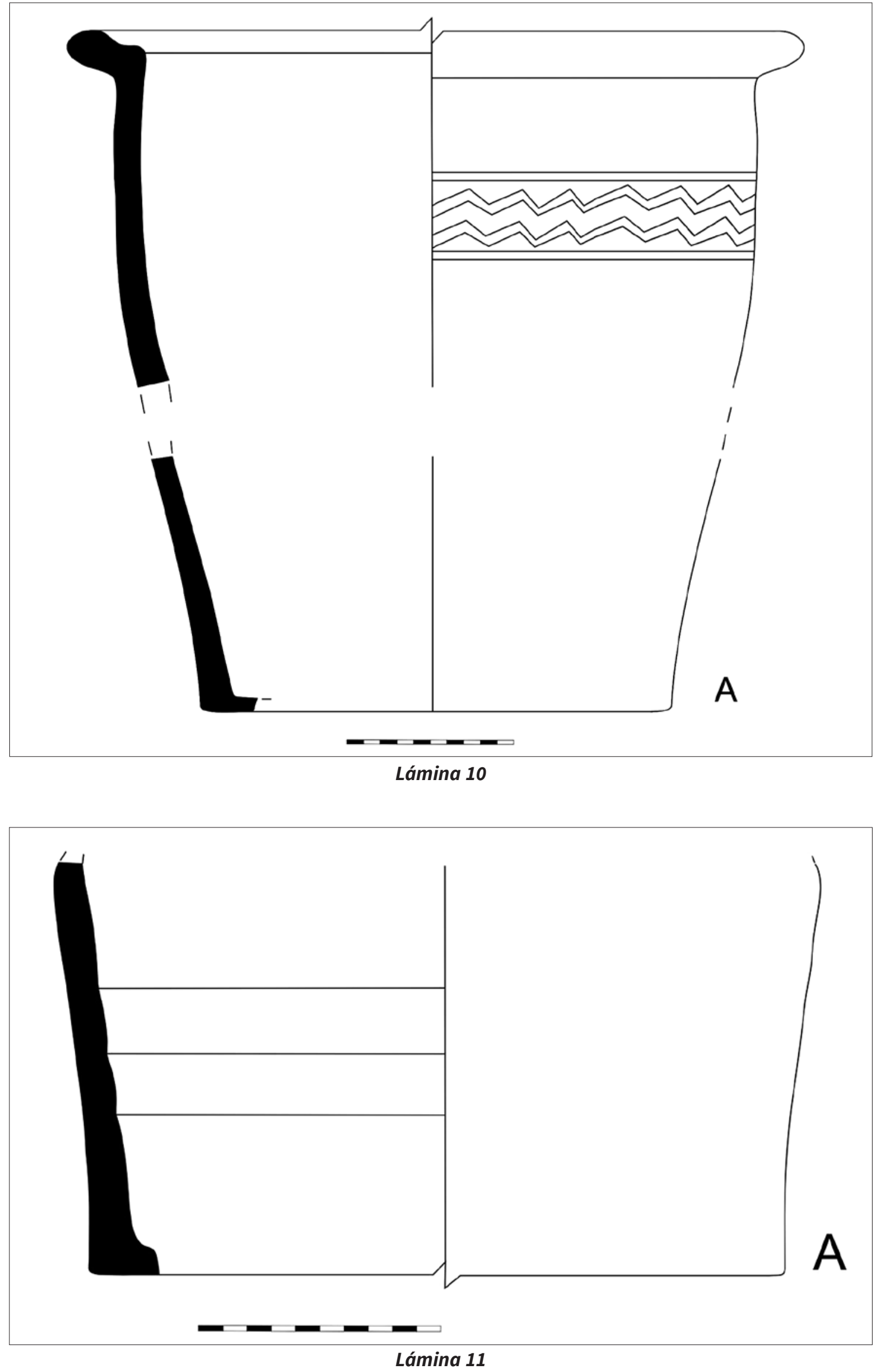
Supone el 100\% de las "serie orzas", y el 2,94\% del total de fragmentos útiles hallados en la alquería.

Ambos fragmentos pertenecen al C-4, y dentro de este a la UE-2 (Lám.10-A) y a la UE-3 (Lám.11-A).

En el primero (Lám.10-A) la pasta está depurada y con desgrasantes de pequeño y medio tamaño compuestos por caliches y esquistos. En el segundo (Lám.11-A) la arcilla también está depurada con desgrasantes de pequeño tamaño y también la pasta es de tonalidades claras.

El borde 10-A tiene boca ancha $(42 \mathrm{~cm})$, paredes de tendencia convergente y cuello inexistente, con labio saliente a modo de ala y moldurado al exterior. La figura 11-A es una base también con paredes de tendencia convergente y con la superficie inferior plana

Sólo el fragmento de borde posee decoración inciso a peine en su exterior enmarcada por cenefas.

El escaso número de ejemplares y la falta de equivalencias en la literatura científica hacen que no podamos incluirlas en un segmento cronológico concreto.

\section{LOS ESPACIOS DE HABITAT. ATRIBUCIONES FUNCIONALES}

Vamos a realizar una aproximación para establecer las funciones que pudieron desempeñar cada unos de los distintos espacios del interior de las viviendas. Para ello nos basaremos en los ajuares cerámicos y en los porcentajes que de estos poseen cada estancia. Es evidente que el escaso número de habitáculos no permite tener una visión global de la estructura urbana del poblamiento, ni de cómo estaban distribuidos los espacios interiores. Creemos que tanto la vivienda del C-4, como las dos fracciones de viviendas del C-6, estarían relacionadas con lugares de hábitat pluricelulares, es decir, que contaban con dos o más espacios individua- lizados y que probablemente se organizaban en torno a un pequeño patio a cielo abierto (GARCÍA PORRAS, 2001: 54), aunque por el carácter aparentemente poco regular de dichos patios, quizá sería más acertado clasificarlos como perteneciente al tipo de "módulos agregados delimitados por un protopatio" (GUTIÉRREZ LLORET, 2013: 13).

En el C-4 existen parte de dos viviendas separadas por una atarjea. La ubicada al este nos muestra dos habitaciones incompletas, ambas con formas rectangulares y paralelas a las curva de nivel del terreno. Han sido identificados 27 fragmentos cerámicos en los que hay un predominio de los relacionados con el servicio de mesa un 22,22\%, 6 jarros/jarritas, servicio de presentación de alimentos, con un 22,22\% y 6 ataifores, serie de exposición al fuego $(18,51 \%)$ con tres marmitas y dos cazuelas, grupo relacionado con la iluminación: tres fragmentos de candiles de pie alto $(11,11 \%)$ y ya en menor proporción artefactos relacionados con usos complementarios y transporte y almacenaje. Por habitáculos se encuentran distribuidos de la siguiente manera:

- UE-3: Seis jarros/jarritas, cuatro ataifores, tres marmitas y dos cazuelas, tres candiles, un alcadafe, una orza y una tapadera.

- UE-6: Dos ataifores, dos alcadafes, un candil y una tapadera.

La situada al oeste está dividida en tres espacios. En el fondo sur una estancia de forma rectangular paralela a las curvas de nivel (UE-2), a la cual se accedía mediante un corredor (UE-4) que podría dar paso a un patio. En el lado este del probable patio, habría otra habitación también de forma rectangular (UE-5). Se han hallado 23 fragmentos cerámicos reconocibles en los que la serie de presentación de alimentos (ocho ataifores, dos platos y una escudilla) supera ampliamente al resto con un índice del 40,74\%. La sigue con un porcentaje bastante inferior (17,39\%) la cerámica de servicio de mesa con cuatro jarritas. Los artefactos de preparación de alimentos, tres cazuelas, ocupan un porcentaje inusualmente bajo (13,04\%). Por último, tam- 
bién tienen representación el grupo de cerámica de usos múltiples (alcadafe) y de vasijas de almacenaje (orza) con dos y un fragmento respectivamente, además de un fragmento de candil y otro de tapadera. Por estancias están repartidos de la siguiente manera:

- UE-2: Seis ataifores, cuatro jarros/jarritas, dos platos, una cazuela, una escudilla y una orza.

- UE-4: Dos cazuelas.

- UE-5: Dos ataifores, dos alcadafes, un candil y una tapadera.

No se ha tenido en cuenta la UE-1 con cinco fragmentos cerámicos, por entender que se trataría de un espacio no perteneciente a las viviendas.

El C-6 está constituido por lo que consideramos la única vivienda completa. La forman tres estancias consecutivas y paralelas a las curvas de nivel (UE-1, UE-2, UE-4), además de dos habitaciones más pequeñas situadas al sur de las anteriores (UE-3 y UE-5). Su planta es en forma de $L$ con un pequeño patio (UE-5). La totalidad del material cerámico de utilidad (diez fragmentos) ha sido hallado en la UE-2. Predominan las cazuelas con cuatro bordes, seguidas de tres fragmentos de ataifores, dos de platos y uno de escudilla.

No podemos atribuirle a estos espacios residenciales una función concreta a tenor del registro cerámico. Esto es así debido a su probable vínculo con depósitos relacionados con un contexto secundario de abandono, respaldado por las fuentes escritas y por el registro arqueológico. Por lo tanto, la relación función-espacio de hábitat no es directa ante la inexistencia de restos inmuebles determinantes. Además, los objetos muebles tampoco aportan suficiente información, por lo que nos vemos ante la imposibilidad de caracterizar funcionalmente a estos espacios arquitectónicos. Hay que tener en cuenta que esta alquería fue destruida por sus propios pobladores a principios de la rebelión que se desarrolló entre los años 1569 y 1571. Los habitantes tuvieron tiempo suficiente para realizar una recogida selectiva de aquellos objetos que tenían mayor interés y que fueran fácilmente transportables. Además, tras su abandono, también se produjo un intenso proceso de erosión que mermó considerablemente la potencia estratigráfica y modificó la posición original de muchos artefactos, dispersándolos por la ladera del cerro.

\section{VALORACIÓN CRONOLÓGICA DE LA ALQUERÍA DE LA VILLETA}

El análisis de los Cortes 4 y 6 presentan una serie de características e indicadores que nos permiten la formulación de una propuesta cronológica con bastante aproximación. Dichas características son las que a continuación resumimos.

En primer lugary en relación con la cerámica de exposición al fuego, existe un predominio de las cazuelas sobre las marmitas, como viene siendo habitual durante el período bajomedieval. Al igual que en el hisn de la Villeta, hay unas determinadas tipologías de cazuelas con bordes en ala sin ningún tipo de recubrimiento, que ya aparecen con las mismas características en época almorávidealmohade y que también son habituales en niveles nazaríes y moriscos del siglo XVI. Estas tipologías están complementadas con una serie de tapaderas, también bizcochadas, en las que se aprecia una capa de tizne que cubre la mayoría de la superficie de dichos fragmentos. Las peculiaridades antes señaladas hacen que propongamos, a modo de hipótesis, que pudiera tratarse de un tipo de cocción en espacios confinados y fuego envolvente en los que no se utilizarían líquidos en la preparación de alimentos. También observamos como determinados tipos de marmitas y cazuelas son indicadores de tipologías cristianas que comienzan a registrarse ya durante el siglo XV y especialmente en el primer cuarto del siglo XVI en ámbitos mudéjares y moriscos.

Los ataifores son también buenas referencias cronológicas. Los tipos quebrados comienzan a aparecer en época almorávide, 
generalizándose su uso ya en el período almohade con vedríos que en un primer momento cubren toda la pieza y tonalidades más diluidas al exterior, para dar paso ya durante el siglo XIII y especialmente en el XIV, a un recubrimiento sólo en el interior. También los vedríos interiores en verde esmeralda tienen unas connotaciones temporales concretas, con una aplicación que comienza a ser habitual durante la segunda mitad del siglo XIII, perdurando hasta bien entrado el siglo XIV. Sin embargo, la aparición de una serie de ataifores de formas también quebradas, pero con un recubrimiento de vedrío melado interior, pueden ser un indicativo de una cerámica elaborada en talleres locales, en manos de artesanos moriscos y con una cronología ya dentro del siglo XVI.

La presencia en los ajuares de platos y escudillas son muestra de formas ajenas a la cultura andalusí y de clara influencia cristiana. Algunos fragmentos decorados nos pueden servir de fósiles-guía, como sería el caso de la escudilla con estilo decorativo "Isabela polychrome", tipología y decoración bien datada dentro del siglo XVI.

Los candiles de pie alto tienen un origen almorávide-almohade y su uso es ya generalizado durante los siglos XIV y XV, prolongándose durante el XVI tanto en ambientes cristianos, como en mudéjares y moriscos. Algunos recubrimientos en verde esmeralda nos indican cronologías relacionadas con la segunda mitad del siglo XIII y con pleno siglo XIV. Los esmaltes estanníferos y los azulesdorados son cubiertas con una clara adscripción nazarí aunque parece que tuvieron continuidad en el siglo XVI.

Los alcadafes con bordes caídos, vedrío en verde esmeralda en su interior y muesca interna entre el borde y la pared, también son atribuibles a los siglos XIV y XV, mientras que los que poseen vedrío verde claro, con unas tonalidades muy marcadas y cenefa por deba- jo del borde interior, tienen un origen cristiano relacionándolos con el siglo XVI.

Las tinajas y la serie jarros-jarritas son menos precisas a la hora de una orientación cronológica. Pero determinadas decoraciones (estampillados en tinajas), recubrimientos y decoraciones en jarros-jarritas (vidriados y esgrafiados), las relacionamos con los períodos almohade y nazarí.

Vemos, por lo tanto, un predominio evidente de tipologías bajomedievales, en concreto pertenecientes a los siglos XIV y XV, junto con formas que ya podemos enmarcar dentro del siglo XVI. También aparecen algunas tipologías residuales de origen almohade, además de determinados artefactos de exposición al fuego que apenas han sufrido modificaciones desde época califal.

\section{CAMBIOS TECNOLÓGICOS Y TIPOLÓGICOS}

Uno de los aspectos de mayor interés que abordamos en este trabajo son los cambios que se produjeron en el registro cerámico de la alquería de la Villeta como reflejo de las profundas transformaciones que ya comenzaron a manifestarse en la sociedad tardonazarí a consecuencia de la constante presión castellana, tanto a nivel militar como por un proceso aculturador que va calando en la fortificada frontera nazarí, proceso que se agudiza tras la conquista territorial.

Los cambios afectan tanto a la tecnología de elaboración como a las tipologías de los artefactos cerámicos. Los ataifores son un claro ejemplo de ello. El ataifor quebrado de origen almohade, generalmente con vedrio interior, borde exvasado y de sección triangular, posee una pasta de tonalidad blanquecina con bandas horizontales discontinuas muy características del período bajomedieval en la Algarbía malagueña ${ }^{14}$, pasta depurada en

\footnotetext{
14 En la actualidad este investigador está realizando un trabajo sobre el poblamiento rural bajomedieval en la subcuenca de río Grande. Es frecuente la observación de ataifores en niveles superficiales con estas características en los que el predominio de estas pastas blanquecinas, formado bandas horizontales, es la tónica dominante.
} 
la que los desgrasantes son prácticamente imperceptibles y con el acabado de la base mediante retorneado ${ }^{15}$. La totalidad de los fragmentos con vedrío interior no melado reúnen estas características (3-C, 3-D, 3-E, 3-G, 3-H, 3-I, 3-J Y 3-K). Sin embargo, si los comparamos con los ataifores "moriscos" encontramos diferencias apreciables. En cuanto a su tipología, los bordes son indiferenciados o redondeados (4-A), con una pasta depurada, aunque con desgrasantes perceptibles. Otra diferencia importante es que el acabado de las bases no es retorneado, sino alisado (4-B, 4-C Y 4-D). También la media en el grosor de sus paredes ${ }^{16}$ varía si comparamos los ataifores que poseen recubrimiento en verde esmeralda o en esmalte blanco en su interior, con aquellos que adscribimos a una cronología relacionada con el siglo XVI y con melado interior. Los primeros tienen un grosor medio máximo de 8,6 mm y un mínimo de 6,3 mm (3-B, 3-C, 3-D, 3-G, 3-H, 3-I, 3-J Y 3-K). Los segundos poseen un grosor medio máximo de 10,5 cm frente al mínimo de 7,4 mm (4-B, 4-C, 4-D y 4-E). Dadas estas diferencias, ¿se elaborarían estos dos modelos de ataifores en diferentes centros de producción y en distintos períodos cronológicos? Las fuentes escritas, aunque escasas, y las diferencias tecnológicas y tipológicas parecen apoyar esta hipótesis.

También determinadas cazuelas muestran tipologías y rasgos tecnológicos diferentes a la tradición andalusí. Así los tipos 1-C, 1-E y $1-G$ proceden de los talleres cristianos y en concreto los fragmentos $1-G$ y $1-H$ pueden tener sus orígenes en los alfares de Paterna, además sus bases, presentan un acabado retorneado, técnica diferente al espatulado de origen almohade-nazarí con que se trataban a los artefactos de exposición al fuego (FERNANDEZ NAVARRO, 2008: 111).

Con relación a los platos y escudillas nos encontramos con tipologías de evidente origen cristiano y reflejo del consumo de alimentos en unidades individualizadas. Las escudillas o cuencos eran habituales en los ajuares altomedievales andalusíes. Así las observamos en las series de Šaqūnda (CASAL et alii, 2005, Figs.12-13) o Cercadilla (FUENTES, 2010, Fig.283, 284 y 285). Sin embargo ya en el Bajo Medievo estas formas desaparecen ${ }^{17}$. La existencia de una serie de platos y escudillas de grandes diámetros (5-A, 5-C, 5-D y 5-G) nos hace sospechar de su posible uso como servicios de presentación de alimentos comunales, siguiendo la costumbre islámica.

Los alcadafes con bordes caídos hacia fuera, vedrío interior en verde diluido y cenefa interior, son ajenos a los relacionados con los tipos nazaríes. Los vedrios de los fragmentos 8-D, 8-E y 8-F presentan unas tonalidades muy brillantes, nacaradas, con un tipo de verde claro que hemos vinculados con un registro arqueológico perteneciente al siglo XVI, lo que muestra cómo se van imponiendo los gustos cristianos en cuanto a los recubrimientos. La cenefa interior también es un rasgo diferenciador, ajeno a los alcadafes tardomedievales. Sabemos que hasta los años sesenta del siglo $X X$ estos lebrillos se utilizaban en las zonas rurales de la subcuenca de río Grande con un carácter multifuncional, destacando su uso para el lavado de ropa, preparación de las masas de determinados productos de repostería y como recipiente de presentación de alimentos para su consumo comunal. Es curioso comprobar cómo las comunidades rurales cristianas también tenían, hasta época

\footnotetext{
15 Según Fernández Navarro: "El proceso de retorneado aprovecha el giro del torno con la pieza centrada en posición invertida, momento en que se raspa la superficie con una herramienta metálica, alaria. Esta herramienta elimina el excedente de barro, aligerando el grosor de las paredes y dando el acabado de la base." (FERNANDEZ NAVARRO, 2008: 111).

16 Para intentar proporcionar un resultado lo más estandarizado posible sólo hemos tomados medidas en el tramo de pared que va desde la base hasta la carena sin tener en cuenta el grosor del repié ni del borde.

17 Hay numerosos yacimientos bajomedievales en que estas tipologías son inexistentes. Sirva como ejemplo el yacimiento de "El Castillejo" de los Guájares (GARCÍA PORRAS, 2001) fechado entre la segunda mitad del siglo XIII y principios del XIV, y el de los Pozos de Cártama (MELERO, 2012b), que abarcaría los siglos XIII, XIV y principios del XV.
} 
contemporánea, la costumbre del consumo de alimentos colectivos en determinadas vasijas $^{18}$, ¿habito de influencia islámica?, o ¿tradición del campesinado cristiano que hunde sus raíces en el Medievo? Por ahora no podemos dar respuesta a estos interrogantes, por lo que se hace necesario profundizar en esta línea de investigación que lleve a aclarar la probable utilización de los servicios comunes de presentación de alimentos en el medio rural, tanto en el ámbito cristiano, como en el andalusí.

\section{CONCLUSIONES}

Podemos diferenciar en la alquería dos períodos cronológicos que fueron consecutivos. El primero correspondería con los siglos XIV y XV, con decoraciones y recubrimientos de los artefactos cerámicos vinculados al período nazarí, aunque tipológicamente sean, en su mayoría, de tradición almohade. La conquista castellana de la zona, junto con la continuidad de la población mudéjar y morisca, marcarán el segundo periodo que asociamos con fragmentos atribuibles ya al siglo XVI, como sucede con estilos decorativos y tipologías de origen cristiano. La cerámica de influencia morisca también deja algún tipo de recubrimiento característico, como serían los melados interiores en escudillas y ataifores, además de bordes indiferenciados o redondeados en estos últimos. Además, las cazuelas con borde en ala, de origen almohade, aumentan sensiblemente la longitud de las alas, predominado las bizcochadas frente a las de vedrío melado interior.

Observamos, por tanto, cómo se va produciendo una paulatina evolución desde formas nazaríes hacia otras que podríamos denominar como propias de la cultura morisca y en donde la aculturación material cristiana es perceptible. La progresiva marginalidad producida por la presión de la sociedad dominante, la perdida de la autonomía política y el aislamiento de estas alquerías en relación con los principales núcleos moriscos del antiguo reino nazarí, hacen que su cultura material vaya adquiriendo una evolución genuina, incluso diferente a la de Granada y su entorno donde la masiva presencia de población morisca, junto con un recuerdo reciente de haber sido la capital del emirato, hacen que se mantenga una cierta continuidad con la cultura material andalusí.

Estos factores también parecen haber derivado hacia unos cambios en los hábitos alimenticios, tradición culinaria de claro origen andalusí, pero que la evolución propia de la cultura morisca hace que tome unas señas de identidad particulares. Reflejo de esto creemos verlo en determinadas tipologías de cazuelas que no poseen vedrío interior y que aparecen siempre recubiertas de tizne, al igual que las tapaderas que asociamos con ellas. Estas tipologías ya se muestran en el califato y continúan hasta el periodo morisco. Será en esta última etapa cuando su presencia se haga más palpable en la alquería de la Villeta con porcentajes elevados dentro de tipo "cazuela". También la presencia de algunas marmitas y cazuelas de grandes dimensiones nos hace pensar en actos culinarios comunales, tales como bodas y fiestas religiosas, que interpretamos como "actos de identidad nacional" ante la creciente presión aculturadora castellana. La presencia de platos y escudillas puede indicar una tendencia hacia el uso de servicio de presentación de alimentos individualizados, propios de las costumbres cristianas.

Otra característica que se observa es que, tras la conquista castellana de la comarca, la población islámica es expulsada de los principales núcleos con categoría de medina como son los casos de Málaga, Dakwan (Coín), Cártama o Alora, quedando relegada a los pequeños núcleos rurales. Esto genera que en los principales centros de fabricación cerámicos, como eran el arrabal de Fontanella para Málaga y el Lexio para Dakwan, se produzca una profunda reestructuración de la

18 Fuentes del autor. En determinados municipios, como es el caso de Monda, la sopa típica del lugar se servía y se sirve en el denominado "dornillo" cuenco de madera que se extrae de los alcornoques y que tiene la función de servicio de exposición de alimentos para su consumo colectivo. Estos cuencos, al ser de madera, no han dejado registro material a través del tiempo. 
producción, en la que los circuitos comerciales nazaríes desaparecen y son sustituidos por los castellanos que ya responden a principios económicos y territoriales distintos. Por lo tanto se genera una dicotomía en la producción cerámica. Por un lado están los talleres rurales mudéjares y posteriormente moriscos, que elaboran un producto cerámico destinado, mayoritariamente, a esta población. Por otro los talleres castellanos con una orientación comercial dirigida a la población de cristianos viejos, pero cuya presencia también es palpable en la zona rural moriscas debido a una creciente aculturación material.

Es llamativo cómo en la publicación que realizaron Acién y Rambla sobre este yacimiento, no se vinculan los Cortes 4 y 6 con elementos materiales de adscripción morisca, cuando está documentado que la alquería estuvo habitada exclusivamente por dicha población hasta el año 1571. Posiblemente estos arqueólogos consideraran que hubo una continuidad, en cuanto a tipologías y decoraciones, entre el siglo XV nazarí y el siglo XVI morisco. Ello es también un indicador del escaso conocimiento que había, y que aún hoy hay, sobre la cultura material morisca, y que sólo en los últimos años parece estar despertando el interés de algunos investigadores.

\section{AGRADECIMIENTOS}

A Antonio Oliver León por su ayuda incondicional y por su magisterio en el dibujo cerámico. A Francisco Melero García experto en cerámica bajomedieval. A Pepe Suárez Padilla por su sapiencia arqueológica. A Esteban García López experto documentalista y bibliógrafo, siempre dispuesto a ayudar. Y finalmente a Virgilio Martínez Enamorado por su presencia permanente y su sabia dirección.

\section{FUENTES DOCUMENTALES}

ARCHIVO HISTÓRICO GENERAL DE SIMANCAS, REGISTRO GENERAL DEL SELLO, Leg. 0269-0085, 1554.g

ARCHIVO HISTÓRICO PROVINCIAL DE GRANADA: LIBROS DE POBLACIÓN, LIBRO 6716, Libro de Repartimiento de Guaro, 1571.

\section{BIBLIOGRAFÍA}

ACIÉN ALMANSA, M., CASTILLO GALDEANO, F., FERNÁNDEZ GUIRADO, Ma. I., MARTÍNEZ MADRID, R., PERAL BEJARANO, C. y VALLEJO TRIANO, A. (1995): "Evolución de los tipos cerámicos en el S. E. de al-Andalus", Véme Colloque International sur la céramique en Méditerranée Occidentale (Rabat 1991), pp. 125-149.

ACIÉN ALMANSA, M. y RAMBLA TORRALBO, J.A. (1990-91): La evolución de un hisn musulmán. Actuación arqueológica en el castillo de Monda, Minake XIII-XIV, Málaga, Diputación de Málaga, pp. 273-293.

AMIGUES, F. y MEQUIDA GARCÍA, M. (1993): Les ateliers et la céramique de Paterna (XIII-XV), Béziers (Francia).

BEJARANO PÉREZ, R. (2004): Los Repartimientos de Málaga, Málaga, Ayt. Málaga, Libro IV.

BEJARANO ROBLES, F. (1985): Los Repartimientos de Málaga, Málaga, Ayt. Malaga, Libro II.

BEJARANO ROBLES, F. (2000): Los Repartimientos de Málaga, Málaga, Ayt. Malaga, Libro V.

CARRIAZO RUBIO, A (ed.). 2003: Historia de los hechos del marqués de Cádiz, Granada, Universidad de Granada.

CASAL, M.T., CASTRO, E., LÓPEZ, R. y SALINAS, E. (2005): "Aproximación al estudio de la cerámica emiral del arrabal de Šaqūnda (Quturba, Córdoba)" en Arqueología y Territorio Medieval, Jaén Universidad de Jaén, pp. 189-213.

CAVILLA SÁNCHEZ-MOLERO, M. (2005): La cerámica almohade de la isla de Cádiz, Cádiz, Universidad de Cádiz.

CAVILLA SÁNCHEZ MOLERO, M. (2007): "La cerámica almohade del suroeste peninsular: producciones estandarizadas" en La cerámica en entornos urbanos y rurales en el Mediterráneo medieval, Ceuta, Museo de Ceuta, pp. 405-456.

COLL CONESA, J. (2009): La cerámica valenciana. Apuntes para una síntesis, Valencia, Rm Edición.

CRUCES BLANCO, E. y RUÍZ POVEDANO, J. M. (2004): Inventario de acuerdos de las Actas Capitulares del Concejo de Málaga, Granada, Universidad de Granada, Diputación de Málaga.

FERNÁNDEZ NAVARRO, E. (2002): Tradición tecnológica de la cerámica de cocina almohade-nazarí, Granada, Grupo de investigación "Toponimia y Arqueología del Reino de Granada".

FLORES ESCOBOSA, I. y MUÑOZ MARTÍN, M. MAR. (1997): "Aproximación al estudio de la cerámica tardo nazarí (Almería y Granada): Pervivencia y cambio" en Transferéncies i Começ de cerámica a L'Europa mediterránia (segles XIV-XVII), Palma de Mallorca, pp. 15-38.

FUENTES SANTOS, M. C. (2010): La Cerámica Medieval de Cercadilla, Córdoba. Tipología, decoración y función, Junta de Andalucía. 
GARCÍA PORRAS, A. (1995): "Cerámica nazarí tardía y cristiana de El Castillejo (Los Guájares, Granada)" en Arqueología y territorio medieval n², Jaén, Universidad de Jaén, pp. 243-258.

GARCÍA PORRAS, A. (2001): La cerámica del poblado fortificado medieval de "El Castillejo", Granada, AthosPergamos.

GÓMEZ BECERRA, A. (1992): El Maraute (Motril). Un asentamiento medieval en la costa de Granada, Motril, Ayto de Motril.

GUTIÉRREZ LLORET, S. (2013): "Casa y casas: reflexiones arqueológicas sobre la lectura social del espacio doméstico medieval" en El Espacio Doméstico en la Península Ibérica Medieval, Pre-actas. Ponencias, Granada, Escuela de Estudios Árabes, CSIC, pp. 7-23.

HERNANDO DEL PULGAR, F. (1780): Crónica de los señores Reyes Católicos don Fernando y doña Isabel de Castilla y Aragón. Capítulo XLII, Alicante, Biblioteca Virtual Miguel de Cervantes, Reproducción digital de la edición original de Valencia de Benito Monfort, Madrid.

LENTISCO NAVARRO, J.L. (2008): “El castillo de Lanjarón (Granada). Un análisis a partir del estudio de la cerámica recogida en la intervención arqueológica de 1995" en Arqueología y Territorio Medieval n 5, Jaén, Universidad de Jaén, pp. 141-159.

MALPICA CUELLO, A. (1999): "Algunas reflexiones sobre el estudio de la cerámica nazarí y mariní", en Cerámica nazari y mariní, Transfretana no 4. Ceuta, Instituto de Estudios Ceutíes, pp. 13-39.

MALPICA CUELLO, A., GARCÍA PORRAS, A., ÁlBAREZ GARCÍA, J, J., CARTA, R., CARVAJAL LÓPEZ, J, C., BONET GARCÍA, M. T. y REYES MARTÍNEZ, E. (2007): "Planteamientos sobre las cerámicas urbanas y rurales del territorio granadino" en La cerámica en entornos urbanos y rurales en el Mediterráneo medieval, Ceuta, Museo de Ceuta, pp. 159-289.

MELERO GARCÍA, F. (2009): "El vertedero medieval de Cártama, Málaga: la cerámica de los pozos de la época emiral y califal", en Arqueología y Territorio Medieval, nº 16, Jaén, Universidad de Jaén, pp. 33-52.

MELERO GARCÍA, F. (2012)a: La cerámica de época nazarí del vertedero medieval de Cártama (Málaga), Granada, Universidad de Granada, Trabajo Fin de Máster, Inédito.

MELERO GARCíA, F. (2012)b: "La cerámica de época nazarí del vertedero medieval de Cártama (Málaga)" en Arqueología y Territorio no 9, Granada, Universidad de Granada, pp. 157-171.

MELERO GARCÍA, F. (2012)c: "El ataifor estampillado andalusí. A propósito del conjunto documentado en el vertedero medieval de Cártama (Málaga)" en Debates de Arqueología Medieval, Granada, Universidad de Granada, pp. 109-128.

MELERO GARCÍA, F. (2013): Actividad Arqueológica Puntual para el estudio de diagnosis del Plan Especial de la Alcazaba-Fortaleza de Vélez-Málaga (Málaga). Informe administrativo inédito depositado en la Delegación Territorial de Cultura y Deporte de Málaga con el número de expediente MA 90/12, Junta de Andalucía.
MESQUIDA GARCÍA, M. (1996): Paterna en el Renacimiento. Resultado de la excavación en un barrio burgués, Valencia.

ORDÓÑEZ FRÍAS, A. (2012): El poblamiento rural andalusí poscalifal en la subcuenca de río Grande. Estructura territorial y pautas de asentamiento, UNED, Trabajo Fin de Máster, Inédito.

PLEGUEZUELO HERNÁNDEZ, A. (1992): "Sevilla y la técnica de cuerda seca: vajilla y azulejos (ss. XV-XVI)" en Atrio 4, pp. 17-30.

PLEGUEZUELO HERNÁNDEZ, A. y LAFUENTE IBAÑEZ, M.P. (1995): "Cerámica de Andalucía occidental (1200-1600)", en Spanish Medieval Ceramics in Spain and the British Isles, Oxford, pp. 217-244.

RETUERCE VELASCO, M. (1998): La cerámica andalusí de la Meseta, Vol. II. Madrid, NRT Editores.

RODRIGUEZ AGUILERA, A. (2000): "Excavación arqueológica en el Carmen de la Concepción (Albaicin, Granada). Datos para una polémica" en Arqueología y Territorio Medieval no 7, Jaén, Universidad de Jaén, pp. 137-156.

RODRIGUEZ AGUILERA, A. y BORDES GARCÍA, S. (2001): "Precedentes de la cerámica granadina moderna: alfareros, centros productores y cerámica" en Cerámica Granadina, siglos XVI-XX, Catálogo de la Exposición "Granada 2001", pp. 51-116.

RODRÍGUEZ AGUILERA, A., GARCÍA-CONSUEGRA, J. M., MORCILLO MATILLAS, J. y RODRÍGUEZ AGUILERA, J. (2011): Cerámica común granadina del seiscientos. A partir de las cerámicas procedentes de la excavación arqueológica de C/Candiota 6, 8 y 10. Granada, Granada, Gespad al-Andalus.

ROSSELLÓ BORDOY, G. (1978): Ensayo de sistematización de la cerámica árabe en Mallorca, Institud d' Estudis Balears.

RUÍZ GARCÍA, A. (2010): "Decoración en la cerámica nazarí en vidriado verde del Museo de la Alhambra. Relaciones con el arte meriní" en Cerámica Nazarí, Coloquio Internacional, Monografía de la Alhambra n³, Granada.

SALADO ESCAÑO, J.B., RAMBLA TORRALBO, A. y MAYORGA MAYORGA, A. (1999): "Nuevas aportaciones sobre la cerámica de época nazarí en la ciudad de Málaga" en Cerámica nazarí y marini, Transfretana no 4, Ceuta, Instituto de Estudios Ceutíes, pp. 221-257.

URBANO PÉREZ, J.A. (1998): La villa de Monda en el siglo XVI. Apeos y primeras ordenanzas, Coin (Málaga), Ediciones Coincidente.

ZOZOYA ESTABEL-HANSEN, J. (1980): “Apercu général sur la cerámique espagnole", Colloque International su la Cerámique Medievale en Mediterranée Occidentale. Valbonne, París, pp. 265-296. 